\title{
Structurally defined zincated and aluminated complexes of ferrocene made by alkali-metal-synergistic syntheses
}

William Clegg, ${ }^{\text {a }}$ Elaine Crosbie, ${ }^{\mathrm{b}}$ Sophie H. Dale-Black, ${ }^{\mathrm{a}}$ Eva Hevia, ${ }^{\mathrm{b}}$ Gordon W. Honeyman, ${ }^{\mathrm{b}}$ Alan R. Kennedy, ${ }^{\mathrm{b}}$ Robert E. Mulvey, ${ }^{\mathrm{b}}{ }^{*}$ Donna L. Ramsay ${ }^{\mathrm{b}}$ and Stuart D.

$$
\text { Robertson }^{\mathrm{b} *}
$$

${ }^{a}$ School of Chemistry, Newcastle University, Newcastle upon Tyne, NE1 7RU, UK.

${ }^{\mathrm{b}}$ WestCHEM, Department of Pure and Applied Chemistry, University of Strathclyde, 295 Cathedral Street, Glasgow, G1 1XL, UK.

\begin{abstract}
Reaction of ferrocene with 1 or 2 molar equivalents of the synergistic-operative bimetallic sodium zincate base TMEDA $\cdot \mathrm{Na}(\mu-\mathrm{TMP})(\mu-t \mathrm{Bu}) \mathrm{Zn}(t \mathrm{Bu})$ yields mainly mono- or di-zincated complexes TMEDA- Na( $\mu$-TMP) $\left[\mu-\left(\mathrm{C}_{5} \mathrm{H}_{4}\right) \mathrm{Fe}\left(\mathrm{C}_{5} \mathrm{H}_{5}\right)\right] \mathrm{Zn} t \mathrm{Bu}(\mathbf{1})$ and [TMEDA $\cdot \mathrm{Na}(\mu-\mathrm{TMP}) \mathrm{Zn}(t \mathrm{Bu})]_{2}\left(\mathrm{C}_{5} \mathrm{H}_{4}\right)_{2} \mathrm{Fe}(2)$. Likewise, the separated pairing of $\mathrm{Li}(\mathrm{TMP})$ and (TMP)Ali $i \mathrm{Bu}_{2}$ in the presence of THF can mono- or dimetalate ferrocene in a synergistic two step lithiation/trans-metal-trapping protocol to give $\mathrm{THF} \cdot \operatorname{Li}(\mu-$ $\mathrm{TMP})\left[\mu-\left(\mathrm{C}_{5} \mathrm{H}_{4}\right) \mathrm{Fe}\left(\mathrm{C}_{5} \mathrm{H}_{5}\right)\right] \mathrm{Al}(i \mathrm{Bu})_{2}(\mathbf{4})$ or $\left[\mathrm{THF} \cdot \mathrm{Li}(\mu-\mathrm{TMP}) \mathrm{Al}(i \mathrm{Bu})_{2}\right]_{2}\left(\mathrm{C}_{5} \mathrm{H}_{4}\right)_{2} \mathrm{Fe}(\mathbf{5}) . \mathrm{In}$ the absence of Lewis donating co-solvents, a four-fold excess of the sodium zincate appears to produce an unprecedented four-fold zincated ferrocene of formula $\mathrm{Na}_{4}(\mathrm{TMP})_{4} \mathrm{Zn}_{4}(t \mathrm{Bu})_{4}\left[\left(\mathrm{C}_{5} \mathrm{H}_{3}\right)_{2} \mathrm{Fe}\right](3)$; whereas when donor solvent is withheld from the lithium/aluminium pairing only dimetalation of ferrocene is possible.
\end{abstract}


Tetrametalation seems to be inhibited by the in situ generation of $\operatorname{TMP}(\mathrm{H})$ via amido basicity which then acts as a Lewis donor towards lithium, preventing inverse-crown formation and preferentially forming the Lewis acid - Lewis base adduct $\left[\mathrm{TMP}(\mathrm{H}) \cdot \operatorname{Li}(\mu-\mathrm{TMP}) \mathrm{Al}(i \mathrm{Bu})_{2}\right]_{2}\left(\mathrm{C}_{5} \mathrm{H}_{4}\right)_{2} \mathrm{Fe} \quad(\mathbf{6})$. With the exception of $\mathbf{3}$, all aforementioned complexes have been characterized by X-ray crystallography, while $\mathbf{1}$ - 6 have also been studied by solution NMR spectroscopic studies.

\section{Introduction}

Alkali Metal Mediated Metallation (AMMM) is a term coined to reflect the positive mediating influence that an alkali metal can have on the metalating power of a less electropositive secondary metal, most notably magnesium, zinc or aluminium, which generally form low polarity metal-carbon bonds of low basicity. ${ }^{1}$ This frequently occurs through the formation of metallate ('ate') complexes which have various formulas of which $\left[(\mathrm{AM})^{+}\left(\mathrm{M}^{\mathrm{x}} \mathrm{R}_{\mathrm{x}+1}\right)^{-}\right](\mathrm{AM}=$ alkali metal, $\mathrm{M}=$ secondary metal, $\mathrm{R}=$ anion) is typical. ${ }^{2}$ Although such a cooperative effect has been recognized for over 60 years since seminal observations of Wittig, ${ }^{3}$ a deeper understanding of this cooperativity and its wider exploitation has only really come to light in the past decade through the studies a number of researchers of whom Knochel, ${ }^{4}$ Mongin, ${ }^{5}$ Uchiyama and Wheatley, ${ }^{6}$ and ourselves have been particularly prominent. ${ }^{7}$ In the best cases the result of combining two distinct organometallic compounds, $A M(R)$ and $\mathrm{M}\left(\mathrm{R}^{\prime}\right)_{2}$ together into a single bimetallic compound is a reagent which in combining the higher reactivity of the alkali metal component with the better selectivity and functional group tolerance of the secondary metal can execute deprotometalation reactions at room temperature (contrast the sub-ambient protocols 
necessary in many organolithium reactions) in non-polar solvents; an improvement on either of the homometallic reagents operating independently. However, not only can AMMM improve on existing homo-metalation protocols it also can bring about novel metalation reactions; for example metalation at typically unreactive or remote sites; or polymetalation of substrates typically strongly resistant to more than one metalation event. The most significant examples of the former reactivity are the recently reported directed ortho-meta' and meta-meta' dimetalations of a range of substituted arenes ${ }^{8}$ by the template ate base $\left[\mathrm{Na}_{2} \mathrm{Mg}(\mathrm{TMP})_{3}(n \mathrm{Bu})\right]_{2}$, which the authors refer to as preinverse crowns. ${ }^{9}$ The latter polymetalations are normally manifested in the form of a supramolecular 'inverse crown' structure, that is a polymetallic cationic ring with the single polyanionic substrate ${ }^{10}$ or multiple monoanionic substrates encapsulated within the core of the cationic ring; ${ }^{9}$ the name inverse crown being derived from the antithetical nature of the positive and negative moieties with respect to the cationdipole sites in a conventional crown ether complex. ${ }^{11}$ One of the most extraordinary examples of this type of chemistry was the unprecedented 1,1',3,3'-tetramagnesiation of ferrocene ${ }^{12}$ along with that of its heavier group 8 congeners ruthenocene and osmocene, ${ }^{13}$ with the resulting tetraanions being captured within a $\left[\mathrm{Mg}_{4} \mathrm{Na}_{4}\left(\mathrm{NiPr}_{2}\right)_{8}\right]^{4+}$ 16-membered inverse-crown ring (figure 1). The formation of this tetramagnesiated ferrocene product was dependent on the identity of the secondary amido component within the ate base since substitution of diisopropylamide, $\mathrm{NiPr}$ by TMP $(2,2,6,6-$ tetramethylpiperidide) resulted in an alternative trinuclear ferrocenophane product in which the three ferrocene molecules were only 1,1 '-dimetalated. ${ }^{14}$ 

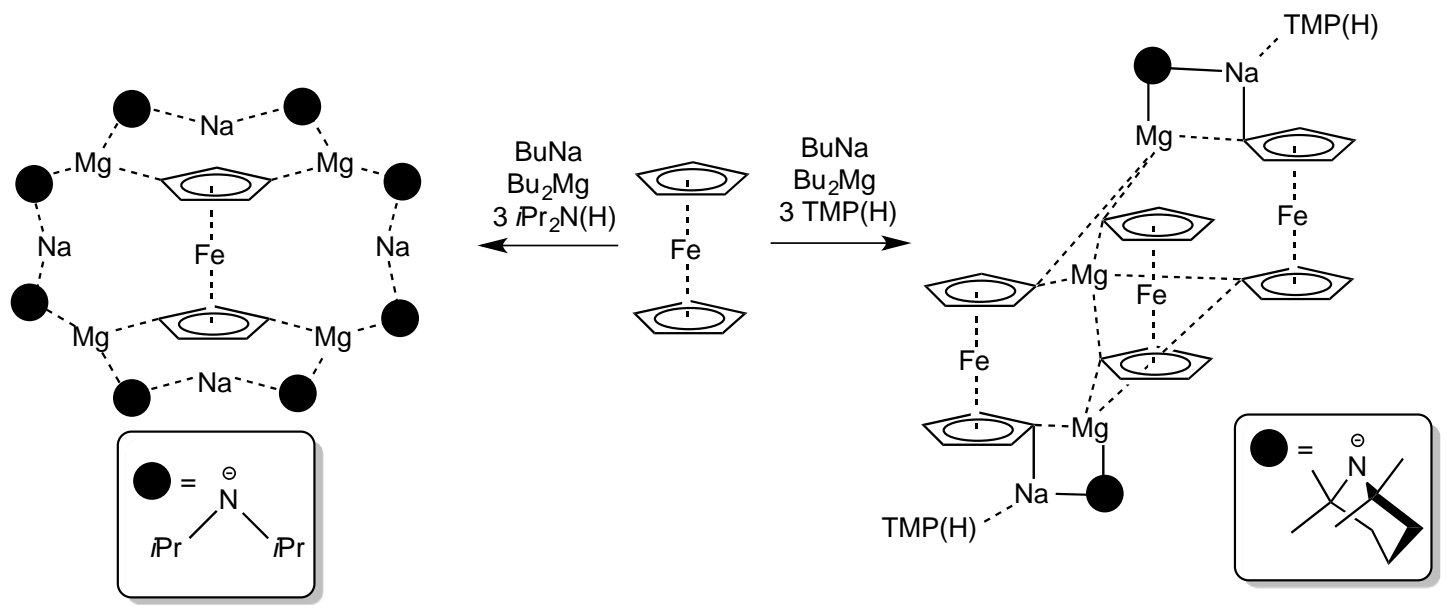

Figure 1 Amide-dependent reactivity of ferrocene with a sodium magnesiate base

Prior to these ate-based direct (i.e., magnesium-hydrogen) metalations, lowerpolarity-metalated ferrocenes have generally been made via salt metathesis approaches often using metal halide starting materials. Figures 2 and 3 show examples of some zincated and aluminated ferrocene complexes, many of which were prepared by such salt metathesis. Zinc species $\mathbf{A}, \mathbf{B}$ and $\mathbf{C}$ are dinuclear ferrocenophanes either mono or dizincated, $\mathbf{E}$ and $\mathbf{F}$ are mononuclear monozincated ferrocenes, while $\mathbf{D}$ is a trinuclear ferrocenophane held together by a single zinc atom. Mononuclear, dinuclear and trinuclear ferrocenophane examples are also shown for the aluminium species, with $\mathbf{H}$ catching the eye with the deprotonated $\mathbf{C}$ atom of the mononuclear ferrocene binding to two $\mathrm{Al}$ centers in a $\mathrm{AlCAlCl}$ ring. Salt metathesis has been one of the most widely utilized synthetic methodologies for transforming numerous polar organometallic compounds (especially those of $\mathrm{Li}, \mathrm{Na}$ and $\mathrm{K}$ ) into derivatives of other metals all across the periodic table. Aside from his many other achievements, Lappert has been probably the World's leading exponent of this approach, having exploited it to synthesize a huge variety of organometallic compounds including alkyl, ${ }^{15}$ amido, ${ }^{16}$ azaallyl ${ }^{17}$ and metallocenyl examples. ${ }^{18}$ 

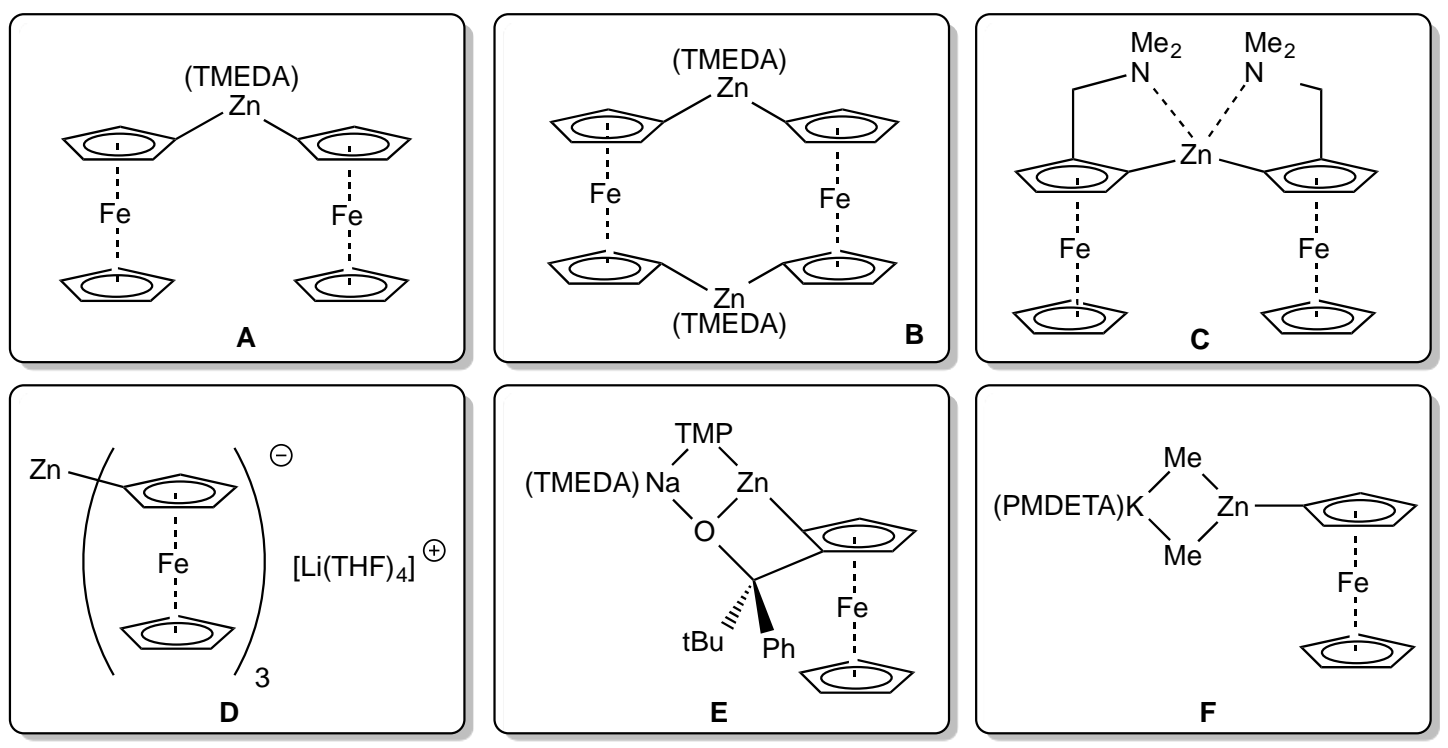

Figure 2 ChemDraw representations of a selection of crystallographically characterized zincated ferrocene molecules. References: $\mathbf{A},{ }^{19} \mathbf{B},{ }^{20} \mathbf{C},{ }^{21} \mathbf{D},{ }^{19} \mathbf{E},{ }^{22} \mathbf{F} .{ }^{23}$
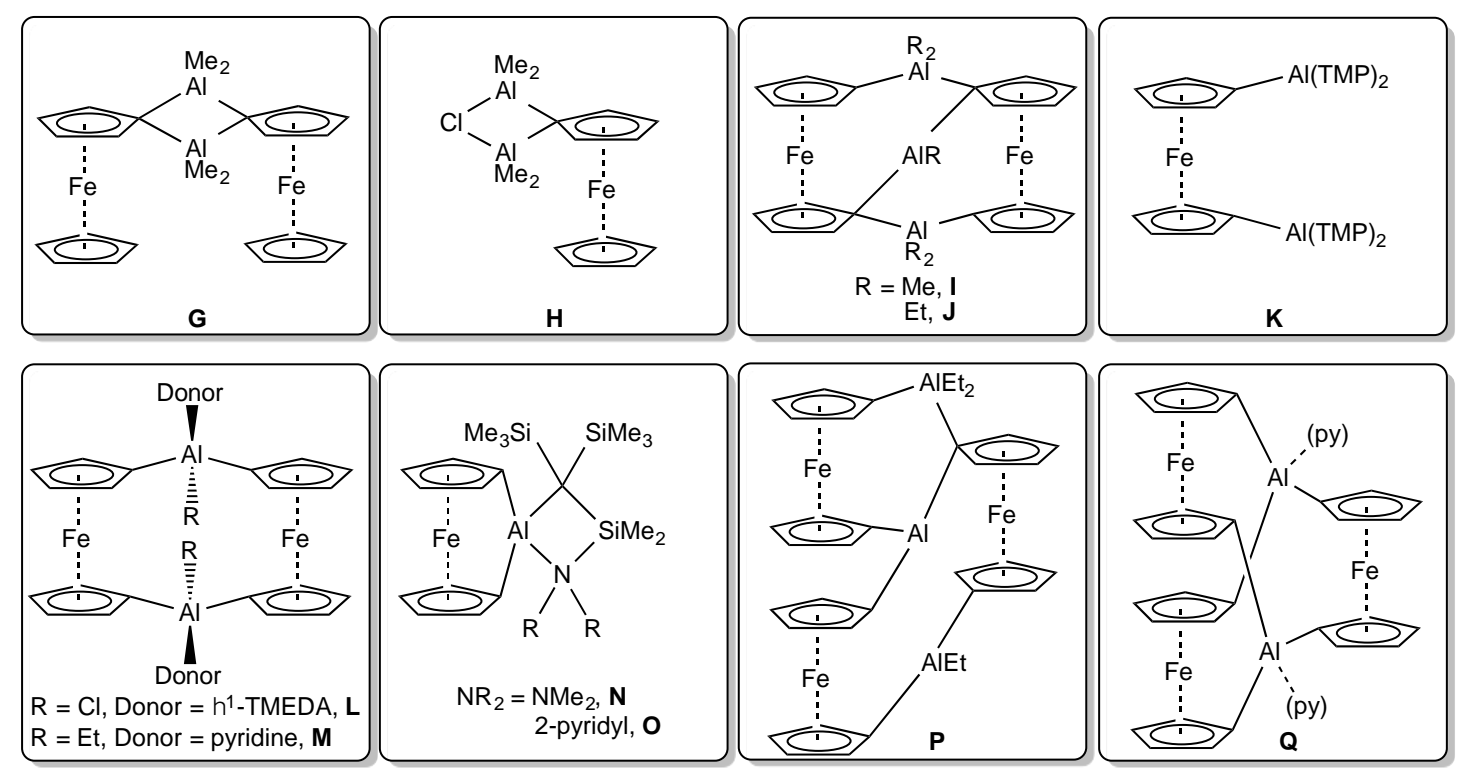

Figure 3 ChemDraw representations of a selection of crystallographically

characterized aluminated ferrocene molecules. References: $\mathbf{G},{ }^{24} \mathbf{H},{ }^{25} \mathbf{I},{ }^{26} \mathbf{J},{ }^{27} \mathbf{K},{ }^{28} \mathbf{L},{ }^{29}$

$$
\mathbf{M},{ }^{30} \mathbf{N},{ }^{31} \mathbf{O},{ }^{32} \mathbf{P},{ }^{33} \mathbf{Q}{ }^{30}
$$

AMMM has the advantage that generally reaction mixtures are homogeneous unlike those in salt metathesis and more importantly, provides access to compounds 
inaccessible via salt metathesis (e.g., the aforementioned tetramagnesiated Group 8 metallocenes). Of course, functionalized ferrocene derivatives are particularly interesting due to their myriad of uses in diverse areas such as materials, ${ }^{34}$ medicinal chemistry, ${ }^{35}$ bioorganometallic chemistry ${ }^{36}$ and as specialty ligands for asymmetric catalysis ${ }^{37}$ amongst others. ${ }^{38}$ We were therefore keen to examine if these discussed precedented metalation patterns, or indeed any others, could be achievable through application of other common bimetallic ate bases at our disposal and now report our findings herein.

\section{Results and Discussion}

\section{Studies of sodium zincate TMEDA $\cdot \mathrm{Na}(\mu-\mathrm{TMP})(\mu-t \mathrm{Bu}) \mathrm{Zn}(t \mathrm{Bu})$}

We commenced our ferrocene ate base studies by investigating the sodium monoamido-bisalkylzincate reagent $\quad \mathrm{TMEDA} \cdot \mathrm{Na}(\mu-\mathrm{TMP})(\mu-t \mathrm{Bu}) \mathrm{Zn}(t \mathrm{Bu}) .{ }^{39} \quad$ Its constituent parts, namely $t \mathrm{Bu}_{2} \mathrm{Zn}, \mathrm{NaTMP}$ and TMEDA are simply mixed together in equimolar quantities (a cocomplexation reaction) to generate it in situ in hexane solution, to which a molar equivalent of ferrocene was introduced (scheme 1).

2

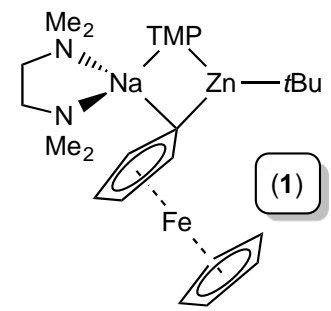

$+2 \mathrm{tBuH}$ $\frac{2 \mathrm{Cp}_{2} \mathrm{Fe}}{\text { hexane }}$

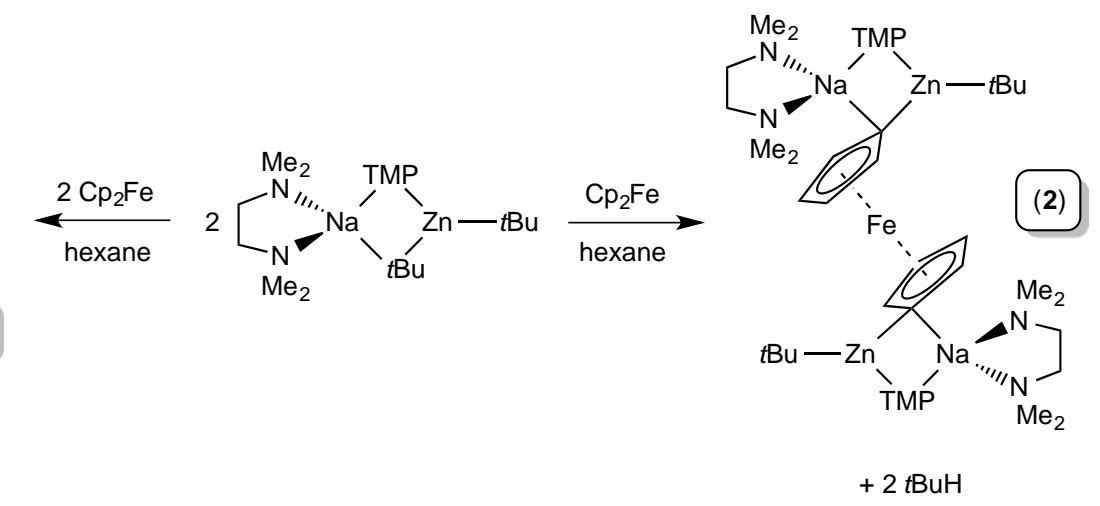

Scheme 1 
After some gentle heating of the solution, a crystalline material was deposited upon bench cooling which was subjected to an X-ray crystallographic structure determination (Figure 4 shows one of the two independent molecules found in the unit cell). This study showed that the bimetallic base had mono-deprotonated ferrocene to give a discrete molecular product of formula TMEDA $\cdot \mathrm{Na}(\mu-\mathrm{TMP})[\mu-$ $\left.\left(\mathrm{C}_{5} \mathrm{H}_{4}\right) \mathrm{Fe}\left(\mathrm{C}_{5} \mathrm{H}_{5}\right)\right] \mathrm{Zn}(t \mathrm{Bu})(\mathbf{1})$. The spirocyclic structure consists of a central NaNZnC core with a terminal $t \mathrm{Bu}$ group plus a TMP anion and a monodeprotonated ferrocene bridging between the metals. TMEDA chelation of sodium completes the structure. This could also be viewed as a trapezium NaNZnC ring with four distinct TMEDA, TMP, $t \mathrm{Bu}$ and ferrocenyl $\left[\left(\mathrm{C}_{5} \mathrm{H}_{4}\right) \mathrm{Fe}\left(\mathrm{C}_{5} \mathrm{H}_{5}\right)\right]$ corners. The zinc and sodium atoms lie in distorted trigonal planar and distorted tetrahedral environments respectively with the sum of the three angles at zinc being exactly $360^{\circ}$ and the $\tau_{4}$ value of sodium being 0.69 , where a value of 1 is perfectly tetrahedral and 0 is perfectly square planar as described by Houser and co-workers. ${ }^{40}$ Such distortion from perfect tetrahedral symmetry is enforced since the sodium atom is the common atom of a spirocycle, resulting in tightening of these angles, with non-cyclic angles being consequently much larger than $109.5^{\circ}$. The central NaNZnC ring is heavily distorted due to the

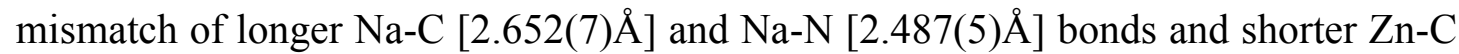
[2.057(7) $\AA$ ] and $\mathrm{Zn}-\mathrm{N}[2.041(5) \AA]$ bonds. There is possibly a degree of coordination between the sodium cation and the $\pi$ system of the deprotonated ferrocene with the distance of sodium to the centroid of the $\mathrm{C}_{5}$ ring being $2.817 \AA$. This value reflects the 'donor' nature of the $\mathrm{C}_{5} \mathrm{H}_{4}$ ring to the Lewis acidic sodium and is marginally longer than that seen in the ferrocene-solvated hexamethyldisilazide dimer $\left[\left\{\mathrm{NaN}\left(\mathrm{SiMe}_{3}\right)_{2}\right\}_{2} \cdot\left(\mathrm{Cp}_{2} \mathrm{Fe}\right)\right]_{\infty}$ which has a corresponding distance of $2.791 \AA{ }^{41}$ perhaps due to the increased coordination number of 1 (4) with respect to that of the 
$\mathrm{NaN}\left(\mathrm{SiMe}_{3}\right)_{2}$ complex (3). Definite cation-anion interactions between a cyclopentadienyl ring and a sodium cation are noticeably shorter, for example only $2.357 \AA$ for unsolvated $[\mathrm{NaCp}]_{\infty}{ }^{42}$ Solvated $\mathrm{NaCp}$ derivatives display understandably longer interactions, such as in dimethoxyethane $(2.55 \AA),{ }^{43} 15$-crown-5 $(2.563 \AA),{ }^{43}$

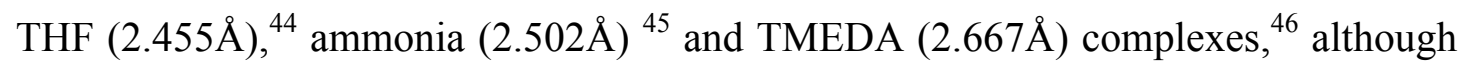
these are still understandably shorter than that in 1. The Na-Cp interaction has virtually no corresponding effect on the $\mathrm{Cp}$-Fe distance. ${ }^{47}$

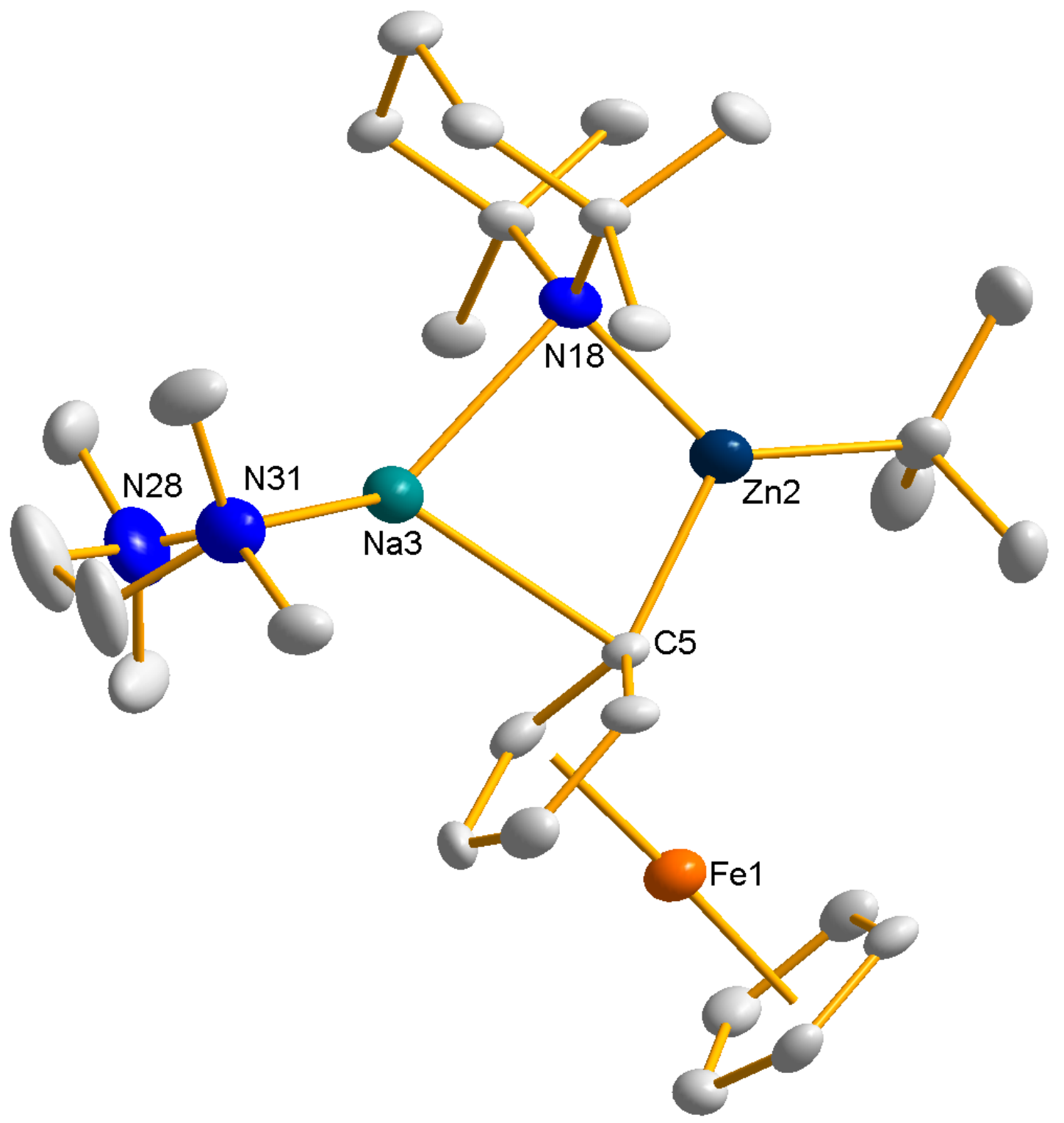


Figure 4 Molecular structure of one of the independent molecules of TMEDA $\cdot \mathrm{Na}(\mu-$ TMP) $\left[\mu-\left(\mathrm{C}_{5} \mathrm{H}_{4}\right) \mathrm{Fe}\left(\mathrm{C}_{5} \mathrm{H}_{5}\right)\right] \mathrm{Zn} t \mathrm{Bu}(\mathbf{1})$. Ellipsoids are shown at $50 \%$ probability level and all hydrogen atoms have been removed for clarity. Selected bond lengths $(\AA)$ and angles $\left({ }^{\circ}\right)$ : Zn2-C5 2.057(7), Zn2-N18 2.041(5), Na3-C5 2.652(7), Na3-N18 2.487(5), Na3-N28 2.587(7), Na3-N31 2.525(6); C5-Zn2-N18 104.5(2), Zn2-N18-Na3 91.0(2), N18-Na3-C5 78.1(2), Na3-C5-Zn2 86.2(2).

The same reaction was then repeated but this time only 0.5 molar equivalents of ferrocene per mole of bimetallic base was introduced (scheme 1). This second reaction produced a different crystalline product in $[\mathrm{TMEDA} \cdot \mathrm{Na}(\mu-$ TMP) $\mathrm{Zn}(t \mathrm{Bu})]_{2}\left(\mathrm{C}_{5} \mathrm{H}_{4}\right)_{2} \mathrm{Fe}$ (2). Though having a similar structure to $\mathbf{1}$, now both cyclopentadienyl rings in $\mathbf{2}$ have been monodeprotonated by the sodium zincate such that the ferrocendiyl molecule acts as a metal-containing bridge between the two bimetallic units (figure 5). The positions of deprotonation on each ring are staggered such that they are almost orthogonal [the dihedral angle formed between the two $\mathrm{Zn}$ $\mathrm{C}_{5 \text { centroid }}$ planes is $\left.84.28(2)^{\circ}\right]$ to minimize the steric clashing of the bulky bimetallic frameworks. This product can formally be considered as that obtained when complex $\mathbf{1}$ is metalated at its intact cyclopentadienyl ring by a further equivalent of the active bimetallic base. The distance of the $\mathrm{C}_{5}$ centroid to sodium is elongated with respect to that in $\mathbf{1}$ at $2.975 \AA$ (c.f. $2.791 \AA$ in $\mathbf{1}$ ) although in this complex the $\mathrm{Na}-\mathrm{C}_{5} \mathrm{H}_{4}$ interaction is probably better defined as $\eta^{2}$ since the distance from sodium to a carbon atom adjacent to the metalated carbon $[2.704(6) \AA]$ is virtually identical to that of the Na- $\mathrm{C}_{\text {metalated }}$ distance $[2.703(6) \AA$; indeed on the other metalated ring the distance to 
the adjacent carbon atom, 2.635(6) $\AA$, is actually shorter than the $\mathrm{Na}-\mathrm{C}_{\text {metalated }}$ distance, $2.762(6) \AA]$.

Due in part to steric clashing between the top and bottom ferrocene appendages, the sodium atom of the second deprotonated ring is noticeably displaced compared to that of the first, with a longer bond to the metalated carbon atom [2.762(6) versus

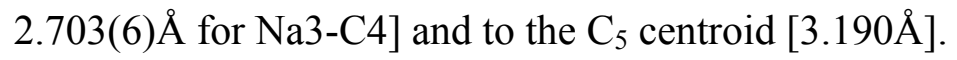

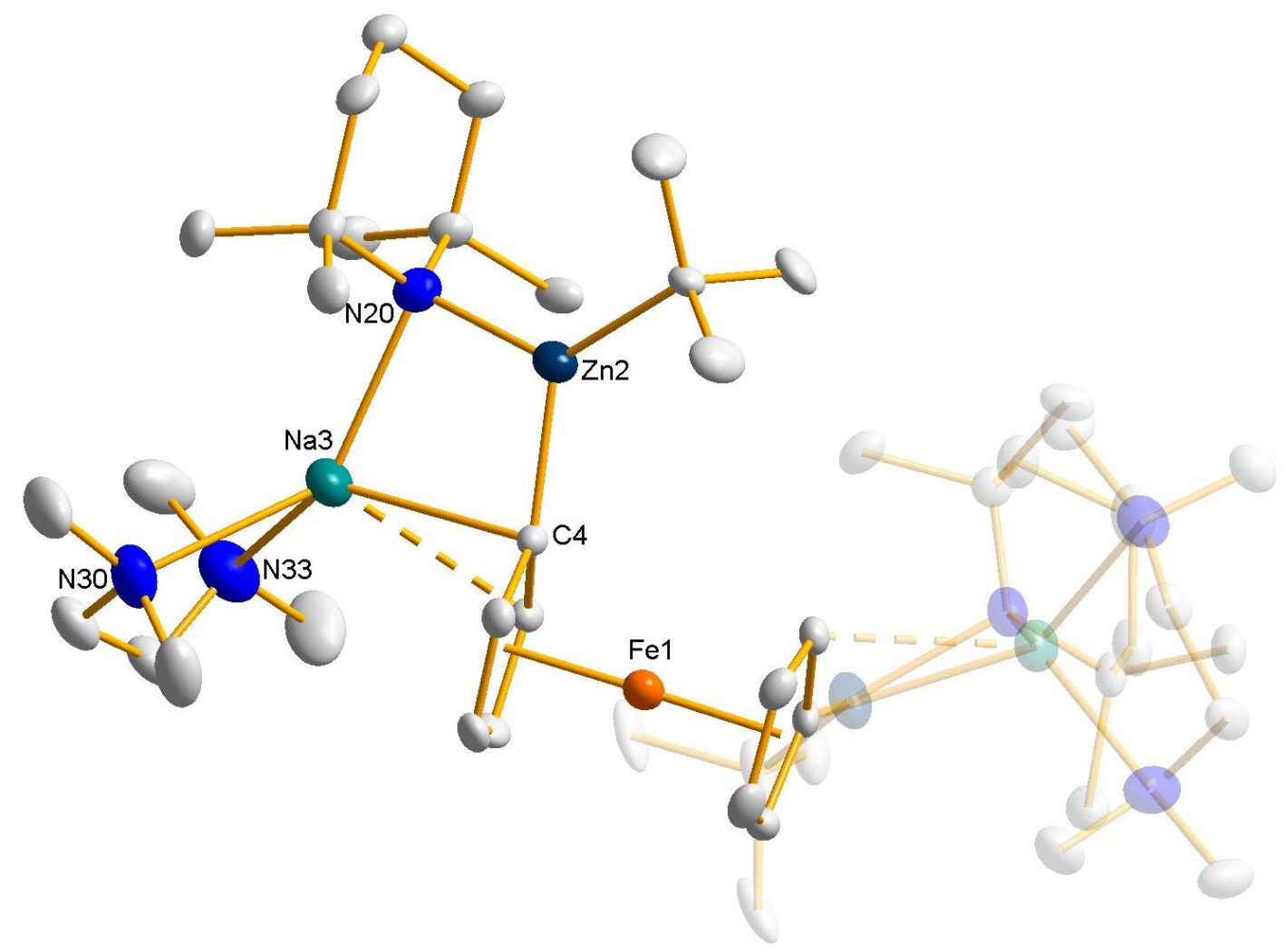

Figure 5 Molecular structure of [TMEDA- $\mathrm{Na}(\mu-\mathrm{TMP}) \mathrm{Zn}(t \mathrm{Bu})]_{2}\left(\mathrm{C}_{5} \mathrm{H}_{4}\right)_{2} \mathrm{Fe} \quad$ (2). Ellipsoids are shown at 50\% probability level and all hydrogen atoms and minor disordered components of TMP and $t \mathrm{Bu}$ groups have been removed for clarity. Selected bond lengths $(\AA)$ and angles $\left({ }^{\circ}\right)$ [values in parentheses represent equivalent parameters on the opposite (transparent) side of molecule]: Zn2-C4 2.045(5) [2.052(5)], Zn2-N20 2.047(4) [2.052(4)], Na3-C4 2.703(6) [2.762(6)], Na3-N20 2.432(4) [2.434(5)], Na3-N30 2.602(5) [2.536(6)], Na3-N33 2.530(5) [2.537(5)]; C4- 
Zn2-N20 105.2(2) [107.2(2)], Zn2-N20-Na3 91.7(2) [90.2(2)], N20-Na3-C4 78.4(2)

[78.7(2)], Na3-C4-Zn2 84.3(2) [81.6(2)].

Notably, the molecular structure shows no evidence of ligand redistribution to give either higher order zincate species or homometallic complexes such as seen previously when utilising the related zincate base TMEDA $\operatorname{Li}(\mu-\mathrm{TMP})(\mu-$ $n \mathrm{Bu}) \mathrm{Zn}(n \mathrm{Bu}) ;{ }^{19}$ or intermolecular aggregation (via $\mathrm{K}-\pi$-arene interactions) as witnessed when ferrocene was metalated using a related potassium zincate base. ${ }^{23}$

Next, complexes 1 and 2 were probed in $\mathrm{C}_{6} \mathrm{D}_{12}$ solution via NMR spectroscopy. Comparing the ${ }^{1} \mathrm{H}$ NMR spectra of the two complexes, it was clear that neither product was pure but contained traces of the other, meaning that final yields are not absolute. We note that complex mixtures of products when metalating ferrocene have been obtained previously, for example by Lerner and co-workers when metalating a diaminoborylferrocene with more than one molar equivalent of homometallic $\operatorname{Mg}(\mathrm{TMP})_{2}$, which contains the same active amido anion as in our zinc and aluminum bases. ${ }^{48}$ The aliphatic region of the spectra of $\mathbf{1}$ and $\mathbf{2}$ was complicated in each case due to the overlapping multiplets of the TMP resonances. However, the region around $4 \mathrm{ppm}$ was indicative of the outcome of the reaction with the mono-zincated species 1 displaying three singlets (resonances were slightly broaded with mutual coupling not noticed) in a 2:2:5 ratio at 3.86, 4.21 and $4.02 \mathrm{ppm}$ respectively, while the di-zincated complex 2 displayed two broad singlets in a $4: 4$ ratio at 3.84 and $4.29 \mathrm{ppm}$. The ${ }^{13} \mathrm{C}$ NMR spectra of these complexes were in agreement although despite repeated attempts with multiple scans we were unable to discern a resonance for the metalated carbon atom of the cyclopentadienyl rings. 
In an attempt to ascertain whether more than twofold zincation of ferrocene could be accessed the reaction stoichiometry was altered to four moles of base per mole of ferrocene. This time no donor solvent (TMEDA) was added since the precedented tetramagnesiated inverse crown complex (vide supra) does not contain any neutral Lewis donor molecules. This reaction mixture precipitated a fine red powder (complex 3), which was collected by filtration and washed. Unfortunately despite several attempts, this powder could not be recrystallized in a quality suitable enough for X-ray crystallographic study. A ${ }^{1} \mathrm{H}$ NMR spectrum of this sparingly soluble product was obtained in $\mathrm{C}_{6} \mathrm{D}_{6}$, which crucially revealed two sets of three equal integration singlets in the diagnostic region of the spectrum around $4 \mathrm{ppm}$, in a ratio of 2.5:1 (figure 6). Resolving three different resonances rather than two tenuously suggests that tetrametalation could have taken place as in tetramagnesiate $\left[\mathrm{Fe}\left(\mathrm{C}_{5} \mathrm{H}_{3}\right)_{2}\right]^{4-}$ complex. ${ }^{12-13}$ To the best of our knowledge no other reaction involving four zinc-hydrogen exchanges has been described in the literature. The fact that there are two sets of these resonances suggests that there are two isomers present in solution, which could be speculated as being an eclipsed and a staggered isomer. Due to the poor solubility of this compound, a useful ${ }^{13} \mathrm{C}$ NMR spectrum of it (and thus a ${ }^{1} \mathrm{H}-{ }^{13} \mathrm{C}$ HSQC spectrum) could not be obtained, precluding definitive assignment of the many overlapping resonances in the aliphatic region.

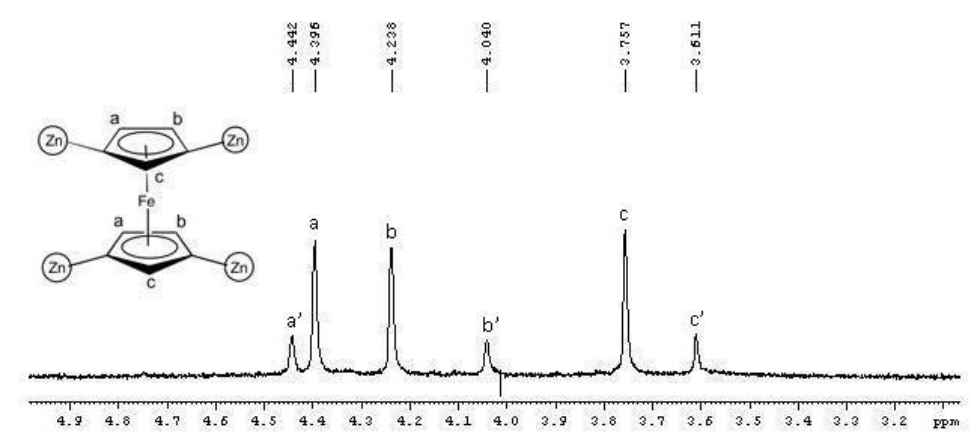


Figure 6 Section of ${ }^{1} \mathrm{H}$ NMR spectrum of putative tetrazincated ferrocene complex $\mathbf{3}$ in $\mathrm{C}_{6} \mathrm{D}_{6}$ solution

\section{Studies of lithium aluminate " $\operatorname{LiAl}(\mathrm{TMP})_{2} i \mathrm{Bu}_{2}$ "}

Following our sodium zincate studies, we moved to another combination with which we have considerable experience, namely the putative lithium/aluminium pairing previously written as " $\mathrm{LiAl}(\mathrm{TMP})_{2} i \mathrm{Bu}_{2}$ ". Originally thought likely to be a highly reactive contacted ion pair primed for direct alumination, ${ }^{49}$ in a parallel study ${ }^{50}$ we recently established it actually exists as a sterically-dictated, non-interacting mixture of its component homometallic compounds, $\mathrm{Li}(\mathrm{TMP})$ and $i \mathrm{Bu}_{2} \mathrm{Al}(\mathrm{TMP})$, which in proton abstraction applications operates via a two step lithiation/aluminium transmetal trapping protocol. The first two reactions (scheme 2) of this bimetallic mixture with one or 0.5 molar equivalents of ferrocene, respectively, in the presence of stoichiometric THF produced crystalline mono and di-deprotonated ferrocene complexes of formula THF $\operatorname{Li}(\mu-\mathrm{TMP})\left[\mu-\left(\mathrm{C}_{5} \mathrm{H}_{4}\right) \mathrm{Fe}\left(\mathrm{C}_{5} \mathrm{H}_{5}\right)\right] \mathrm{Al}(i \mathrm{Bu})_{2}(\mathbf{4}$, figure 7) and $\left[\mathrm{THF} \cdot \mathrm{Li}(\mu-\mathrm{TMP}) \mathrm{Al}(i \mathrm{Bu})_{2}\right]_{2}\left(\mathrm{C}_{5} \mathrm{H}_{4}\right)_{2} \mathrm{Fe}(\mathbf{5}$, figure 8$)$ respectively. As is the case with complexes $\mathbf{1}$ and $\mathbf{2}$, the secondary metal of lower electropositivity than lithium has replaced the abstracted hydrogen atom with the alkali-metal lying outside the plane of the $\mathrm{C}_{5} \mathrm{H}_{4}$ ring, although as the smaller alkali-metal in these cases is less $\pi$-philic, it is best described as a $\eta^{1}$ interaction. In both cases, the lithium atoms occupy a threecoordinate $(1 \mathrm{xC} ; 1 \mathrm{xN} ; 1 \mathrm{xO})$ environment with a bridging TMP and a neutral THF completing their coordination spheres. 


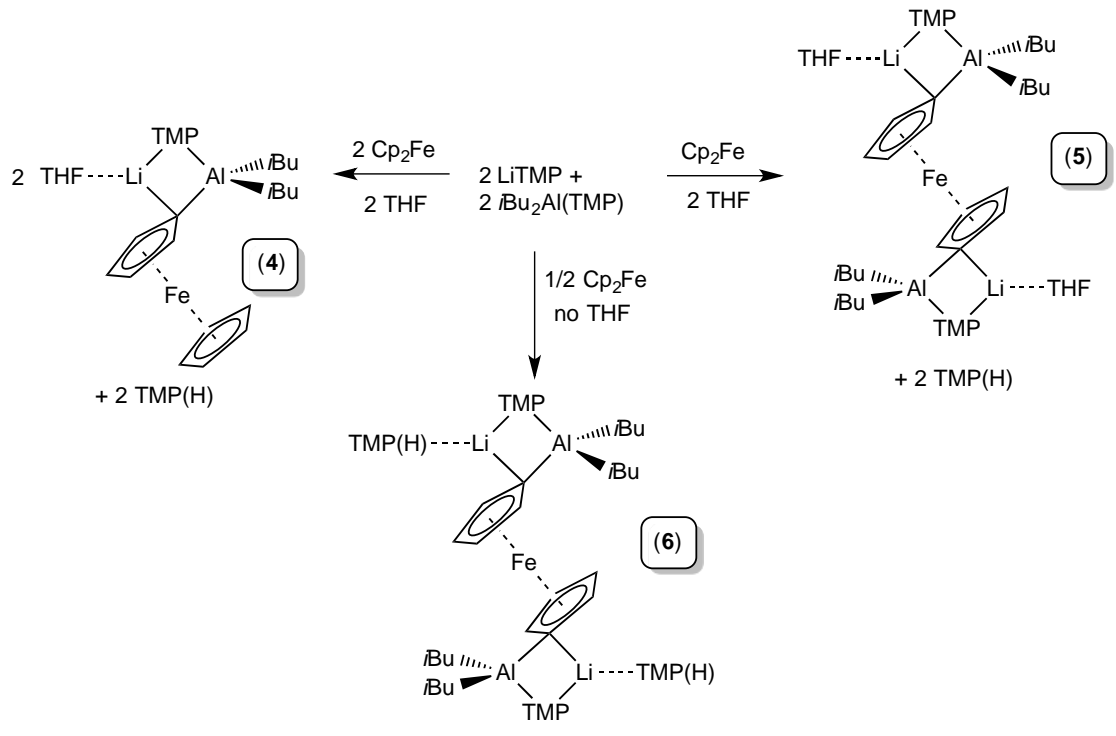

Scheme 2

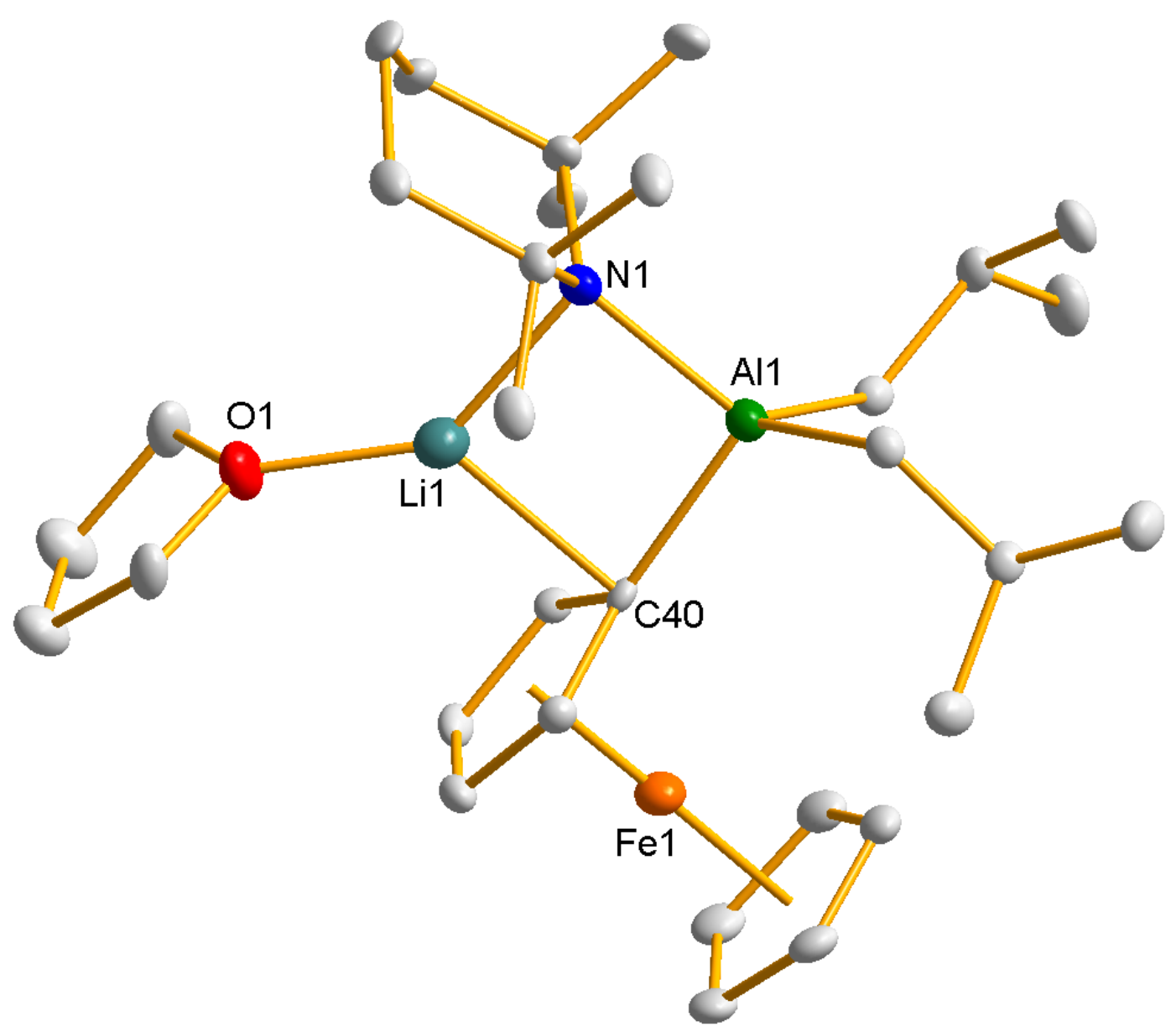


Figure 7 Molecular structure of the monoaluminated ferrocene THF $\operatorname{Li}(\mu-\mathrm{TMP})[\mu-$ $\left.\left(\mathrm{C}_{5} \mathrm{H}_{4}\right) \mathrm{Fe}\left(\mathrm{C}_{5} \mathrm{H}_{5}\right)\right] \mathrm{Al}(i \mathrm{Bu})_{2}(4)$. Ellipsoids are shown at 50\% probability level and all hydrogen atoms have been removed for clarity. Selected bond lengths $(\AA)$ and angles $\left({ }^{\circ}\right)$ : Al1-C40 2.039(3), Al1-N1 1.994(2), Li1-C40 2.188(6), Li1-N1 2.005(5), Li1-O1 1.866(6); C40-Al1-N1 96.1(1), Al1-N1-Li1 89.3(2), N1-Li1-C40 91.2(2), Li1-C40Al1 83.3(2).

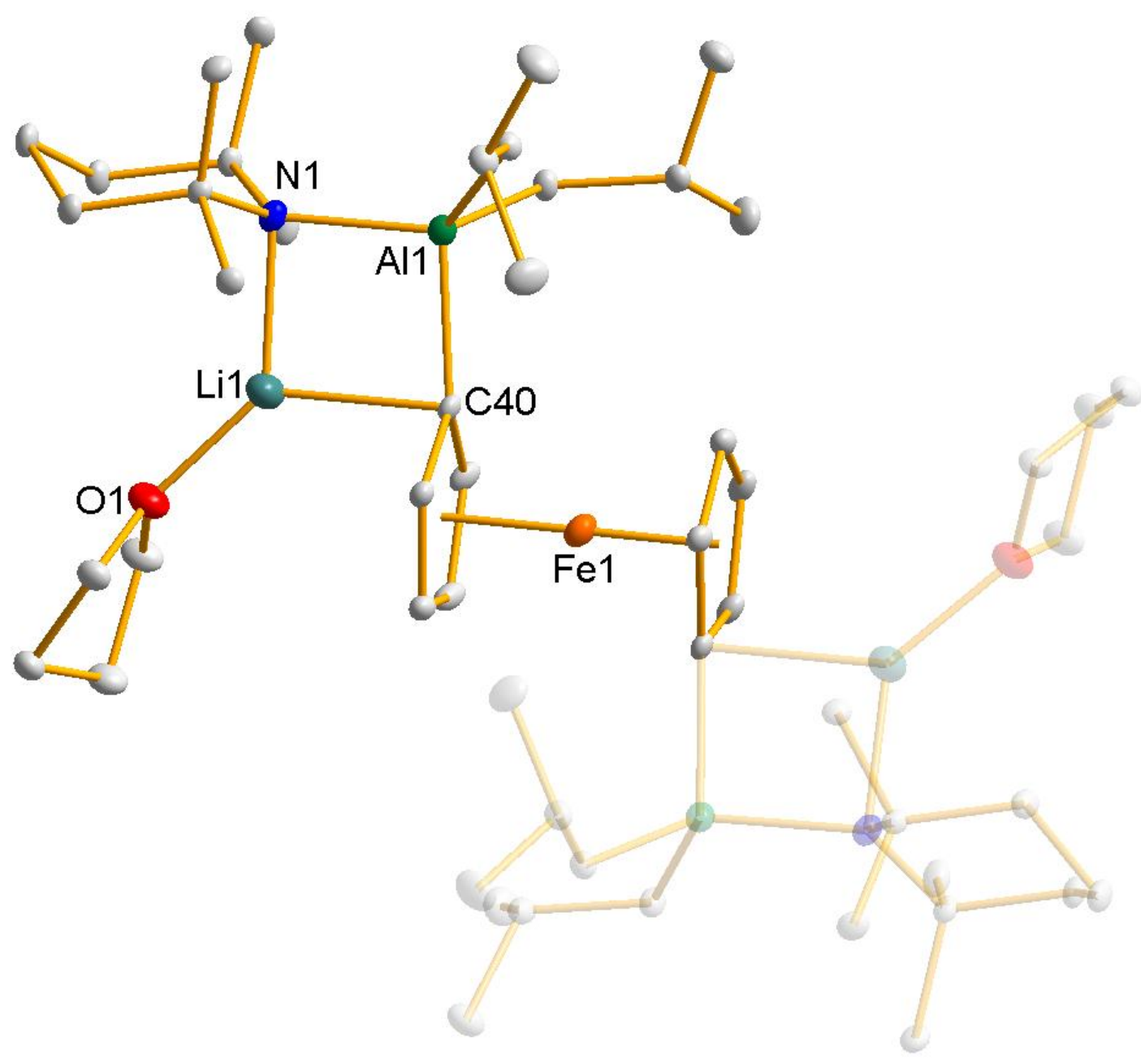

Figure 8 Molecular structure of the dialuminated ferrocene [THF.Li( $\mu-$ TMP)Al $\left.(i \mathrm{Bu})_{2}\right]_{2}\left(\mathrm{C}_{5} \mathrm{H}_{4}\right)_{2} \mathrm{Fe}(5)$. Ellipsoids are shown at 50\% probability level and all hydrogen atoms have been removed for clarity. Symmetry operation to generate second half of structure: 2.5-x, y, 2-z. Selected bond lengths $(\AA)$ and angles $\left(^{\circ}\right)$ : Al1- 
C40 2.053(1), Al1-N1 1.996(1), Li1-C40 2.194(3), Li11-N1 2.032(2), Li1-O1

1.884(2); C40-Al1-N1 97.3(4), Al1-N1-Li1 88.2(1), N1-Li1-C40 91.9(1), Li1-C40Al1 82.5(1).

The local environments around the deprotonated ferrocene molecules are unsurprisingly similar in complexes $\mathbf{4}$ and $\mathbf{5}$. Specifically, there is very little difference in the dimensions of the four-membered, four-element Li-N-Al-C rings of each as demonstrated by comparison of their Al-C [2.039(1) and 2.053(1) $\AA$

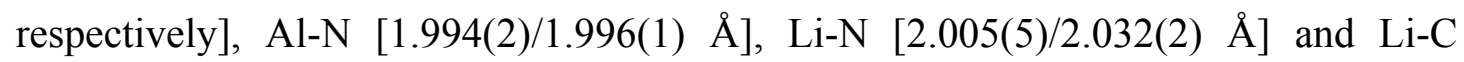
[2.188(6)/2.194(3) A] bond distances. In complex 5, the position of deprotonation of the cyclopentadienyl rings (that is the newly formed Al-C bonds) are perfectly staggered due to its centrosymmetric nature.

Taking complex $\mathbf{4}$ as an example (although the same principle applies to the second $\mathrm{Cp}$ ring to yield 5) the mechanism is, as mentioned earlier, likely to involve a two step process of lithiation, which occurs in only a poor yield using Li(TMP) as a metalating agent, followed by trans-metal trapping with the soluble monomer (TMP)Ali $\mathrm{Bu}_{2}$ (scheme 3). Although not directly involved in the first step as it cannot cocomplex with LiTMP nor deprotonate ferrocene, the presence of the aluminium reagent is necessary for the reaction to proceed by mopping up the product on the right hand side of the equilibrium and thus this can be considered a synergistic reaction. Indeed this process is likely at play in other metalations of functionalized ferrocene with bimetallic combinations ${ }^{51}$ which are sterically prevented (through the use of bulky amides such as TMP) from combining into a contacted molecular bimetallic ate type base. $^{52}$ This contrasts with $\mathrm{TMEDA} \cdot \mathrm{Na}(\mu-\mathrm{TMP})(\mu-t \mathrm{Bu}) \mathrm{Zn}(t \mathrm{Bu})$, which has been 
proven to be a contacted ion pair zincate that generally deprotonates aromatic substrates intramolecularly with sodium acting as a Lewis acidic coordination point.

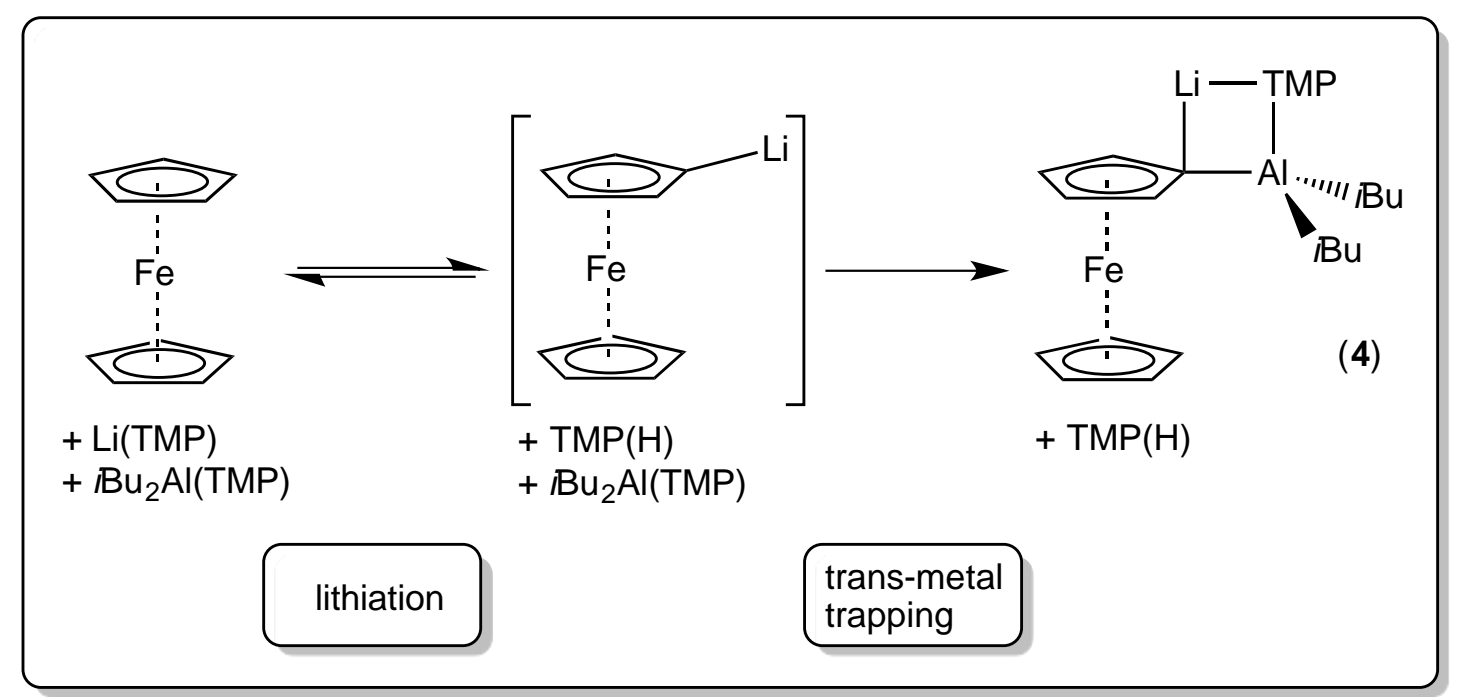

Scheme 3 Proposed two-step lithiation/trans-metal-trapping mechanism for monoalumination of ferrocene.

Finally, we attempted to prepare a tetra-aluminated ferrocene complex by adding 0.25 molar equivalents of ferrocene to the synergistic lithium/aluminium mixture (scheme 2). Following the preparation of $\mathbf{3}$, no donor solvent was included as this could potentially cap the Lewis acidic metal and prevent formation of the inverse crown ring. However, the crystalline material $\left[\mathrm{TMP}(\mathrm{H}) \cdot \mathrm{Li}(\mu-\mathrm{TMP}) \mathrm{Al}(i \mathrm{Bu})_{2}\right]_{2}\left(\mathrm{C}_{5} \mathrm{H}_{4}\right)_{2} \mathrm{Fe} \mathbf{6}$ (figure 9) resulting from this reaction turned out to be only a di-aluminated derivative (akin to 5). Interestingly, in the absence of THF the non-volatile, bulky amine $\mathrm{TMP}(\mathrm{H})$, liberated as a co-product from the deprotonation reaction due to amine basicity, acts as a Lewis donor, capping the lithium and preventing the bimetallic units from linking up further into a ring as seen in the sodium magnesiate inverse crown in Figure 1. Dative TMP $(\mathrm{H}) \cdots \mathrm{Li}$ contacts are relatively rare in the literature 
with the bond length in complex 6 [mean, 2.229 $]$ ] being longer than those previously reported in $\mathrm{TMP}(\mathrm{H}) \cdot \operatorname{LiN}(t \mathrm{Bu}) \mathrm{B}(\mathrm{Ph})(\mathrm{TMP}) \quad[2.155(5) \AA],^{53} \quad \mathrm{TMP}(\mathrm{H}) \cdot \operatorname{Li}(\mu-i \mathrm{Bu})(\mu-$ $\mathrm{TMP}) \mathrm{Al}_{i \mathrm{Bu}_{2}}[2.165(5) \AA]^{54}$ or $[\mathrm{TMP}(\mathrm{H}) \cdot \mathrm{LiI}]_{4}[$ mean, $2.104 \AA] .^{49 \mathrm{f}}$

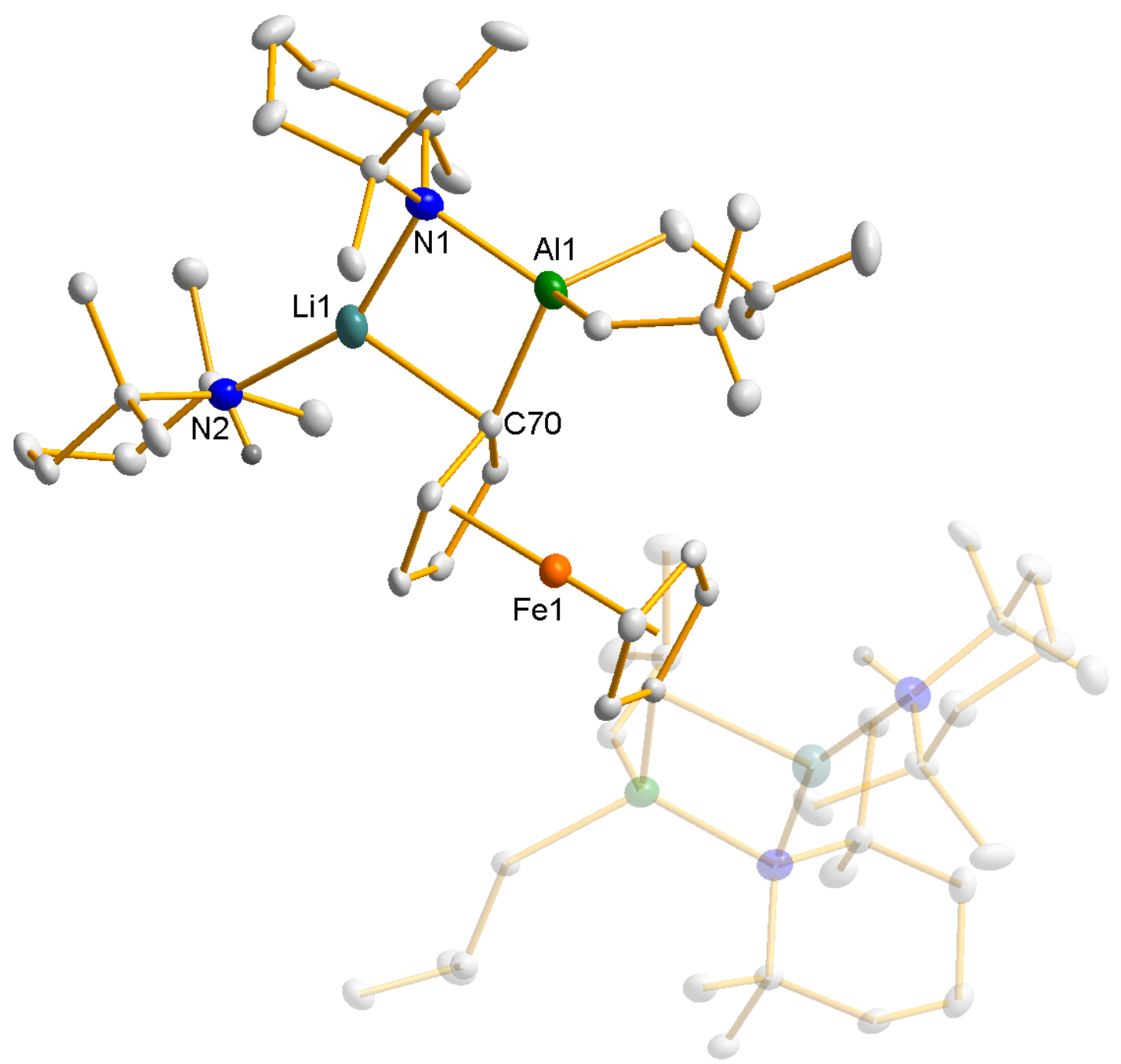

Figure 9 Molecular structure of the dialuminated ferrocene $[\mathrm{TMP}(\mathrm{H}) \cdot \operatorname{Li}(\mu-$ TMP)Al $\left.(i \mathrm{Bu})_{2}\right]_{2}\left(\mathrm{C}_{5} \mathrm{H}_{4}\right)_{2} \mathrm{Fe}(6)$. Ellipsoids are shown at 50\% probability level and all hydrogen atoms [except on TMP(H)] have been removed for clarity. Selected bond lengths $(\AA)$ and angles $\left(^{\circ}\right)$ [values in parentheses represent equivalent parameters on the opposite (transparent) side of molecule]: Al1-C70 2.043(3) [2.030(3)], A11-N1 1.996(2) [1.993(2)], Li1-C70 2.248(6) [2.297(5)], Li11-N1 2.106(5) [2.095(6)], Li1- 
N2 2.223(5) [2.236(6)]; C70-Al1-N1 97.5(1) [97.8(1)], Al1-N1-Li1 89.2(2) [90.7(2)],

N1-Li1-C70 88.4(2) [87.2(2)], Li1-C70-Al1 84.3(2) [84.3(2)].

The inability of this synergistic lithium-aluminium base mixture to effect a dual deprotonation of each ring due to the presence of (in this case in situ generated) donor is reminiscent of the alkali-metal mediated metalation of other simple arenes such as benzene or toluene. While the donor free base $\mathrm{NaMg} n \mathrm{Bu}(\mathrm{TMP})_{2}$ can smoothly dideprotonate these aromatic rings (note that in the toluene case the most acidic methyl substituent is left untouched), ${ }^{55}$ solvation of the base with TMEDA prior to introducing the substrate results in only monodeprotonation. ${ }^{56}$ Likewise, and more directly related to this work, the $\mathrm{NaTMP} / t \mathrm{Bu}_{2} \mathrm{Zn}$ combination will dideprotonate benzene prior to TMEDA addition but only monodeprotonate it if TMEDA is in the reaction mixture at the onset (scheme 4). ${ }^{57} \mathrm{We}$ note here that it is extremely challenging to doubly deprotonate a non-metallocenic cyclopentadiene ring with to the best of our knowledge the only example being the $n \mathrm{BuLi}$ induced deprotonation of $\mathrm{Cp}^{-}$in the molecular square complex $[\operatorname{Li}(\mu-\mathrm{TMP}) \operatorname{Li}(\mu-\mathrm{Cp})]_{4}$ to generate $[\{\operatorname{Li}(\mu-$ TMP $\left.) \operatorname{Li}(\mu-\mathrm{Cp})\}_{4} \mathrm{Li}_{6}(n \mathrm{Bu})_{2}\right]$ as reported by Klett and coworkers. ${ }^{58}$

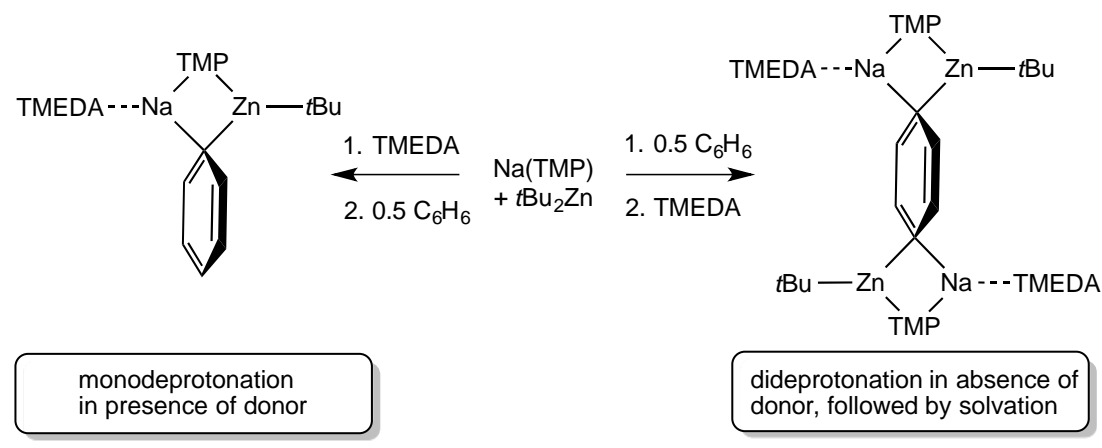

Scheme 4 
Unlike in complex 5, the deprotonated rings in $\mathbf{6}$ are not perfectly staggered, with the Al-C bonds lying at $145.65(2)^{\circ}$ to one another. The larger steric bulk of the TMP(H) donor ligand with respect to THF may be a factor in the elongation of the Li-N and Li-C bonds within the four membered ring to 2.106(5) and 2.248(6) $\AA$ respectively (c.f. Li-N $[2.005(5) / 2.032(2) \AA]$ and Li-C $[2.188(6) / 2.194(3) \AA]$ in THF solvated complexes $\mathbf{4}$ and $\mathbf{5}$ respectively).

Complexes 4 (in $\mathrm{C}_{6} \mathrm{D}_{12}$ solution) and 6 (in $\mathrm{C}_{6} \mathrm{D}_{6}$ solution, as the resonances in $\mathrm{C}_{6} \mathrm{D}_{12}$ were very broad) proved to be of higher purity than the aforementioned zinc complexes with only resonances corresponding to their molecular structures being seen in their solution ${ }^{1} \mathrm{H}$ spectra. This was further corroborated through the ${ }^{7} \mathrm{Li}$ NMR spectra, which showed only one sharp resonance. In the case of $\mathbf{5}$, a small amount of complex 4 was evidently present in $\mathrm{C}_{6} \mathrm{D}_{12}$ solution as seen in both the ${ }^{1} \mathrm{H}$ and ${ }^{7} \mathrm{Li}$ spectra. Again, the ${ }^{1} \mathrm{H}$ spectra were very cluttered in the aliphatic region although the region around $4 \mathrm{ppm}$ was particularly diagnostic due to the lucid resolution of the cyclopentadienyl resonances of ferrocene. Monodeprotonated complex 4 displayed three characteristic singlets in a 2:2:5 ratio at $4.00,4.25$ and 4.09 ppm while the dideprotonated complexes gave a pair of equal intensity singlets at 3.97/4.47 ppm (5) and 4.15/4.29 ppm (6). Interestingly, the lower field resonance in complex 6 is considerably broadened. Once again, a resonance for the metalated carbon atom could not be identified in the ${ }^{13} \mathrm{C}$ spectra.

\section{Conclusion}

This study has revealed that the sodium zincate reagent TMEDA $\cdot \mathrm{Na}(\mu-\mathrm{TMP})(\mu-$ $t \mathrm{Bu}) \mathrm{Zn}(t \mathrm{Bu})$ can successfully perform one or two zinc-hydrogen exchange reactions 
with ferrocene to afford TMEDA $\cdot \mathrm{Na}(\mu-\mathrm{TMP})\left[\mu-\left(\mathrm{C}_{5} \mathrm{H}_{4}\right) \mathrm{Fe}\left(\mathrm{C}_{5} \mathrm{H}_{5}\right)\right] \mathrm{Zn}(t \mathrm{Bu}) \quad \mathbf{1}$ or [TMEDA $\cdot \mathrm{Na}(\mu-\mathrm{TMP}) \mathrm{Zn}(t \mathrm{Bu})]_{2}\left(\mathrm{C}_{5} \mathrm{H}_{4}\right)_{2} \mathrm{Fe} 2$, respectively. Though the number of $\mathrm{C}-\mathrm{H}$ deprotonations essentially matches the stoichiometry of the base used in the reaction ( 1 or 2 equivalents respectively), the reactions are not clean in that there are always trace amounts of $\mathbf{2}$ found in solid samples of $\mathbf{1}$ and vice versa. The crystal structures obtained are similar to those previously observed using other metal bases. Where a sodium zincate could be unique is in generating the suspected tetradeprotonated ferrocene 3. Zinc ate reagents are not generally known for multiple (more than two) zinc-hydrogen exchanges within the same molecule nor generating inverse crown architectures unlike their magnesium counterparts (the best example being the aforementioned tetra-magnesiated ferrocene) so the full formulation and structural characterization of such a polyzincated species would be a particularly intriguing finding though this has proved elusive in this study. The aluminum reactions appear to be cleaner giving rise to the monodeprotonated ferrocene $\mathrm{THF} \cdot \mathrm{Li}(\mu-\mathrm{TMP})[\mu-$ $\left.\left(\mathrm{C}_{5} \mathrm{H}_{4}\right) \mathrm{Fe}\left(\mathrm{C}_{5} \mathrm{H}_{5}\right)\right] \mathrm{Al}(i \mathrm{Bu})_{2} \quad \mathbf{4}$, and the dideprotonated ferrocene [THF. $\mathrm{Li}(\mu-$ TMP)Al $\left.(i \mathrm{Bu})_{2}\right]_{2}\left(\mathrm{C}_{5} \mathrm{H}_{4}\right)_{2} \mathrm{Fe} \mathbf{5}$, though unlike the aforementioned zincate reactions which are direct zinc-hydrogen exchange processes these reactions are two step lithiation, trans-metal(aluminum)-trapping (or indirect aluminations) akin to salt metathesis processes but with the advantage that the trapping agent, $i \mathrm{Bu}_{2} \mathrm{Al}(\mathrm{TMP})$, is hydrocarbon soluble. Unlike from the zincation (or magnesiation) reaction, a tetraaluminated ferrocene has remained elusive, even in the total absence of neutral Lewis donating solvent, with only a di-aluminated product solvated by the in situ generated secondary amine, $\left[\mathrm{TMP}(\mathrm{H}) \cdot \mathrm{Li}(\mu-\mathrm{TMP}) \mathrm{Al}(i \mathrm{Bu})_{2}\right]_{2}\left(\mathrm{C}_{5} \mathrm{H}_{4}\right)_{2} \mathrm{Fe} \quad \mathbf{6}$, being identified. Tentatively (as only a few reactions have been considered for this effect), this suggests that multiple deprotonations of a substrate, often manifested as the guest of 
an inverse-crown type structure, cannot be obtained when a non-volatile Lewis donating secondary amine is generated as a part of the original deprotonation reaction and that overall alkyl basicity (that is, in the sense that the alkyl group deprotonates TMP $(\mathrm{H})$ to enable TMP to re-enter the coordination sphere of the deprotonated substrate as discussed in several papers ${ }^{59}$ ) with its concomitant generation of nondonating, volatile alkanes is more suited for such polymetalation reactions. Work is ongoing to prove or disprove this hypothesis.

\section{Experimental}

\section{General experimental}

All reactions and manipulations were performed under a protective argon atmosphere using either standard Schlenk techniques or a glove box. Hexane and THF were dried by heating to reflux over sodium benzophenone ketyl and then distilled under nitrogen prior to use. TMEDA was distilled over $\mathrm{CaH}_{2}$ and stored over $4 \AA$ molecular sieves. TMP(H) was stored over $4 \AA$ molecular sieves. $n \mathrm{BuLi}$ solution $(1.6 \mathrm{M}$ in hexanes), $i \mathrm{Bu}_{2} \mathrm{AlCl}$ and ferrocene were purchased commercially from Sigma-Aldrich and used as received. $t \mathrm{Bu}_{2} \mathrm{Zn}$ was prepared by a literature method. ${ }^{60} \mathrm{NMR}$ spectra were recorded on a Bruker AV $400 \mathrm{MHz}$ spectrometer operating at $400.13 \mathrm{MHz}$ for ${ }^{1} \mathrm{H}, 155.47 \mathrm{MHz}$ for ${ }^{7} \mathrm{Li}$ and $100.62 \mathrm{MHz}$ for ${ }^{13} \mathrm{C}$. All ${ }^{13} \mathrm{C}$ spectra were proton decoupled. ${ }^{1} \mathrm{H}$ and ${ }^{13} \mathrm{C}$ spectra were referenced to the residual solvent signal while ${ }^{7} \mathrm{Li}$ spectra were referenced to an external sample of $\mathrm{LiCl}$ in $\mathrm{D}_{2} \mathrm{O}$. Satisfactory elemental analyses of the air sensitive products 1 (co-crystallized with $\mathbf{2}$ ), $\mathbf{2}$ (co-crystallized with 1), 3 (too air sensitive) and $\mathbf{6}$ (decomposed on balance due to increased lability of donor amine) could not be obtained. 


\section{X-ray crystallography}

Crystallographic data were collected on Nonius KappaCCD or Oxford Diffraction instruments with Mo K $\alpha$ radiation $(\lambda=0.71073 \AA)$. Structures were solved using SHELXS-97, ${ }^{61}$ while refinement was carried out on $F^{2}$ against all independent reflections by the full-matrix least-squares method using the SHELXL-97 program. ${ }^{61}$ All non-hydrogen atoms were refined using anisotropic thermal parameters. Selected crystallographic details and refinement details are given in table S1 of supplementary information. CCDC-1036678 to CCDC-1036682 contain the supplementary crystallographic data for this paper. These can be obtained free of charge from the Cambridge Crystallographic Data Centre via www.ccdc.cam.ac.uk/data_request/cif. 
Synthesis of TMEDA $\cdot \mathrm{Na}(\mu-\mathrm{TMP})\left[\mu-\left(\mathrm{C}_{5} \mathrm{H}_{4}\right) \mathrm{Fe}\left(\mathrm{C}_{5} \mathrm{H}_{5}\right)\right] \mathrm{Zn} t \mathrm{Bu}(\mathbf{1})$

A Schlenk flask was charged with $t \mathrm{Bu}_{2} \mathrm{Zn}(0.358 \mathrm{~g}, 2 \mathrm{mmol})$ which was dissolved in hexane $(10 \mathrm{~mL})$. In a separate Schlenk flask BuNa $(0.160 \mathrm{~g}, 2 \mathrm{mmol})$ was suspended in hexane $(10 \mathrm{~mL})$ and TMP(H) $(0.34 \mathrm{~mL}, 2 \mathrm{mmol})$ was added via syringe to give a creamy white suspension which was allowed to stir for an hour. After this time the $t \mathrm{Bu}_{2} \mathrm{Zn}$ solution was introduced to the mixture via syringe to give a yellow suspension. TMEDA $(0.30 \mathrm{~mL}, 2 \mathrm{mmol})$ was added via syringe and the reaction mixture was heated gently to form a yellow solution. Once this mixture had returned to ambient temperature ferrocene $(0.372,2 \mathrm{mmol})$ was added via solid addition tube and this was heated gently to give a transparent solution. Upon cooling the solution at $-35^{\circ} \mathrm{C}$ a crop of orange crystals of $\mathbf{1}$ formed $(0.22 \mathrm{~g}$, not an absolute yield due to traces of $\mathbf{2}$ also being present).

${ }^{1} \mathrm{H}$ NMR (400.13 MHz, $\left.\mathrm{C}_{6} \mathrm{D}_{12}, 300 \mathrm{~K}\right): \delta 1.06$ [6H, s, TMP Me], 1.20 [6H, s, TMP Me], $1.21[9 \mathrm{H}, \mathrm{s}, t \mathrm{Bu}], 1.23\left[2 \mathrm{H}, \mathrm{m}, \mathrm{TMP} \beta-\mathrm{CH}_{2}\right], 1.54\left[2 \mathrm{H}, \mathrm{m}, \mathrm{TMP} \beta-\mathrm{CH}_{2}\right], 1.71$ [2H, m, TMP $\gamma-\mathrm{CH}_{2}$ ], 2.06 [12H, s, TMEDA Me], 2.16 [4H, s, TMEDA $\mathrm{CH}_{2}$ ], 3.86 $\left[2 \mathrm{H}, \mathrm{s}, \mathrm{C}_{5} \mathrm{H}_{4} \mathrm{Fe}\right], 4.02\left[5 \mathrm{H}, \mathrm{s}, \mathrm{C}_{5} \mathrm{H}_{5} \mathrm{Fe}\right], 4.21\left[2 \mathrm{H}, \mathrm{s}, \mathrm{C}_{5} \mathrm{H}_{4} \mathrm{Fe}\right]$.

${ }^{13} \mathrm{C}$ NMR (100.63 MHz, $\left.\mathrm{C}_{6} \mathrm{D}_{12}, 300 \mathrm{~K}\right): \delta 19.4$ [CMe $\mathrm{CM}_{3}$ ], 20.5 [TMP $\gamma$ ], 35.4 [TMP Me], 35.5 [ $\underline{\mathrm{Me}}_{3}$ ], 35.7 [TMP Me], 40.5 [TMP $\beta$ ], 46.6 [TMEDA Me], 53.2 [TMP $\alpha$ ], 58.0 [TMEDA CH $\left.\mathrm{CH}_{2}\right], 68.5\left[\mathrm{C}_{5} \mathrm{H}_{5} \mathrm{Fe}\right], 70.4\left[\mathrm{C}_{5} \mathrm{H}_{4} \mathrm{Fe}\right], 76.1\left[\mathrm{C}_{5} \mathrm{H}_{4} \mathrm{Fe}\right]$

Synthesis of [TMEDA $\cdot \mathrm{Na}(\mu-\mathrm{TMP}) \mathrm{Zn}(t \mathrm{Bu})]_{2}\left(\mathrm{C}_{5} \mathrm{H}_{4}\right)_{2} \mathrm{Fe}(\mathbf{2})$

A Schlenk flask was charged with $t \mathrm{Bu}_{2} \mathrm{Zn}(0.358 \mathrm{~g}, 2 \mathrm{mmol})$ which was dissolved in hexane $(10 \mathrm{~mL})$. In a separate Schlenk flask BuNa $(0.160 \mathrm{~g}, 2 \mathrm{mmol})$ was suspended in hexane $(10 \mathrm{~mL})$ and $\mathrm{TMP}(\mathrm{H})(0.34 \mathrm{~mL}, 2 \mathrm{mmol})$ was introduced via syringe. The 
resulting creamy white suspension was then stirred for an hour. After this time the $t \mathrm{Bu}_{2} \mathrm{Zn}$ solution was added via syringe to give a yellow suspension to which TMEDA $(0.30 \mathrm{~mL}, 2 \mathrm{mmol})$ was also added. This mixture was then heated gently to form a yellow solution. Once this solution had cooled to ambient temperature ferrocene $(0.186,1 \mathrm{mmol})$ was added via solid addition tube and this was heated gently to give a transparent solution. Upon cooling this solution at $-35^{\circ} \mathrm{C}$ a crop of orange crystals formed of $2(0.98 \mathrm{~g}$, not an absolute yield due to traces of $\mathbf{1}$ also being present) were obtained.

${ }^{1} \mathrm{H}$ NMR (400.13 MHz, $\left.\mathrm{C}_{6} \mathrm{D}_{12}, 300 \mathrm{~K}\right): \delta 1.02$ [6H, s, TMP Me], 1.18 [6H, s, TMP Me], $1.22[9 \mathrm{H}, \mathrm{s}, t \mathrm{Bu}], 1.24\left[2 \mathrm{H}, \mathrm{m}, \mathrm{TMP} \beta-\mathrm{CH}_{2}\right], 1.55\left[2 \mathrm{H}, \mathrm{m}, \mathrm{TMP} \beta-\mathrm{CH}_{2}\right], 1.71$ [2H, m, TMP $\gamma-\mathrm{CH}_{2}$ ], 2.13 [12H, s, TMEDA Me], 2.22 [4H, s, TMEDA $\mathrm{CH}_{2}$ ], 3.84 [4H, s, $\left.\mathrm{C}_{5} \mathrm{H}_{4} \mathrm{Fe}\right], 4.29\left[4 \mathrm{H}, \mathrm{s}, \mathrm{C}_{5} \mathrm{H}_{4} \mathrm{Fe}\right]$.

${ }^{13} \mathrm{C}$ NMR (100.63 MHz, $\left.\mathrm{C}_{6} \mathrm{D}_{12}, 300 \mathrm{~K}\right): \delta 20.5$ [TMP $\gamma$ ], 17.6 [ $\mathrm{CMe}_{3}$ ], 35.2 [TMP Me], 35.7 [TMP Me], 35.8 [Cيе 3 ], 40.4 [TMP $\beta$ ], 46.7 [TMEDA Me], 53.2 [TMP $\alpha$ ], 58.1 [TMEDA CH 2$], 71.4\left[\mathrm{C}_{5} \mathrm{H}_{4} \mathrm{Fe}\right], 75.9\left[\mathrm{C}_{5} \mathrm{H}_{4} \mathrm{Fe}\right]$.

Synthesis of $\mathrm{Na}_{4}(\mathrm{TMP})_{4} \mathrm{Zn}_{4}(t \mathrm{Bu})_{4}\left[\left(\mathrm{C}_{5} \mathrm{H}_{3}\right)_{2} \mathrm{Fe}\right](\mathbf{3})$

A Schlenk flask was charged with $t \mathrm{Bu}_{2} \mathrm{Zn}(0.358 \mathrm{~g}, 2 \mathrm{mmol})$ which was dissolved in hexane $(10 \mathrm{~mL})$. In a separate Schlenk flask BuNa $(0.160 \mathrm{~g}, 2 \mathrm{mmol})$ was suspended in hexane $(10 \mathrm{~mL})$ and $\operatorname{TMP}(\mathrm{H})(0.34 \mathrm{~mL}, 2 \mathrm{mmol})$ was added via syringe, the resulting creamy white suspension being allowed to stir for an hour. Next the $t \mathrm{Bu}_{2} \mathrm{Zn}$ solution was added via syringe followed by ferrocene $(0.09 \mathrm{~g}, 0.5 \mathrm{mmol})$ via a solid addition tube. This mixture was stirred for 2 hours during which time the suspension changed from yellow to orange to red. The resulting red powder of $\mathbf{3}$ was collected 
via filtration, washed with hexane and dried in vacuo $(0.08 \mathrm{~g}, 10 \%$, based on the above formula being correct).

Synthesis of THF $\cdot \operatorname{Li}(\mu-\mathrm{TMP})\left[\mu-\left(\mathrm{C}_{5} \mathrm{H}_{4}\right) \mathrm{Fe}\left(\mathrm{C}_{5} \mathrm{H}_{5}\right)\right] \mathrm{Al}(i \mathrm{Bu})_{2}(\mathbf{4})$

In a Schlenk flask, $n$ BuLi $(1.25 \mathrm{~mL}, 1.6 \mathrm{M}$ in hexanes, $2 \mathrm{mmol})$ was suspended in hexane $(10 \mathrm{~mL})$ and $\operatorname{TMP}(\mathrm{H})(0.34 \mathrm{~mL}, 2 \mathrm{mmol})$ was added via syringe, before $i \mathrm{Bu}_{2} \mathrm{AlCl}(0.38 \mathrm{~mL}, 2 \mathrm{mmol})$ was introduced via syringe producing a white suspension almost immediately. This suspension was stirred for one hour and then filtered through Celite and glass wool to remove solid LiCl. In a separate Schlenk flask LiTMP was prepared in hexane $(10 \mathrm{~mL})$ from a mixture of $n \mathrm{BuLi}(1.25 \mathrm{~mL}, 2$ mmol $)$ and $\mathrm{TMP}(\mathrm{H})(0.34 \mathrm{~mL}, 2 \mathrm{mmol})$. The $i \mathrm{Bu}_{2} \mathrm{AlTMP}$ solution was added to the LiTMP solution via cannula to give a colourless solution. THF $(0.16 \mathrm{~mL}, 2 \mathrm{mmol})$ and ferrocene $(0.372 \mathrm{~g}, 2 \mathrm{mmol})$ were added producing an orange solution which was stirred overnight at room temperature and then allowed to stand until a crop of orange needles of 4 formed $(0.52 \mathrm{~g}, 48 \%)$.

${ }^{1} \mathrm{H}$ NMR $\left(400.13 \mathrm{MHz}, \mathrm{C}_{6} \mathrm{D}_{12}, 300 \mathrm{~K}\right): \delta 0.37\left[4 \mathrm{H}, \mathrm{d},{ }^{3} J(\mathrm{H}, \mathrm{H})=5.03 \mathrm{~Hz}, 2 \times \mathrm{CH}_{2}\right.$ of $i \mathrm{Bu}$ ], $0.75\left[2 \mathrm{H}, \mathrm{t},{ }^{3} J(\mathrm{H}, \mathrm{H})=12.44 \mathrm{~Hz}, 2 \times \mathrm{CH}_{2}\right.$ of TMP], 1.09 [12H, 2 x overlapping $\mathrm{d},{ }^{3} J(\mathrm{H}, \mathrm{H})=6.49 \mathrm{~Hz}, 4 \times \mathrm{CH}_{3}$ of $\left.i \mathrm{Bu}\right], 1.27\left[7 \mathrm{H}, \mathrm{s}, 2 \times \mathrm{TMP} \mathrm{Me}+1 \times \mathrm{CH}_{2}\right.$ of TMP (confirmed by HSQC)], 1.33 [6H, s, 2 x TMP Me], $1.48\left[2 \mathrm{H}, \mathrm{d},{ }^{3} J(\mathrm{H}, \mathrm{H})=12.43 \mathrm{~Hz}\right.$, $2 \times \beta \mathrm{CH}_{2}$ of TMP], 1.73 [4H, s, $2 \times \beta \mathrm{CH}_{2}$ of THF], 1.84 [1 $\mathrm{H}, \mathrm{m}, 1 \times \gamma \mathrm{CH}_{2}$ of TMP], $2.14\left[2 \mathrm{H}, \operatorname{sept},{ }^{3} J(\mathrm{H}, \mathrm{H})=6.42 \mathrm{~Hz}, 2 \times \mathrm{CH}\right.$ of $\left.i \mathrm{Bu}\right], 3.50\left[4 \mathrm{H}, \mathrm{m}, 2 \times \alpha^{2} \mathrm{CH}_{2}\right.$ of THF], $4.00\left[2 \mathrm{H}, \mathrm{s}, \mathrm{C}_{5} \mathrm{H}_{4} \mathrm{Fe}\right], 4.09\left[5 \mathrm{H}, \mathrm{s}, \mathrm{C}_{5} \mathrm{H}_{5} \mathrm{Fe}\right], 4.25\left[2 \mathrm{H}, \mathrm{s}, \mathrm{C}_{5} \mathrm{H}_{4} \mathrm{Fe}\right]$.

${ }^{13} \mathrm{C}$ NMR $\left(100.63 \mathrm{MHz}, \mathrm{C}_{6} \mathrm{D}_{12}, 300 \mathrm{~K}\right): \delta 18.7$ [TMP $\gamma$ ], 25.3 [THF $\beta \mathrm{CH}_{2}$ ], 28.0 $\left[\mathrm{CH}_{2} \underline{\mathrm{CHMe}}_{2}\right], 29.2\left[\mathrm{CH}_{2} \mathrm{CHMe}_{2}\right], 29.8$ [TMP Me], $31.0\left[\underline{\mathrm{CH}}_{2} \mathrm{CHMe}_{2}\right], 36.8$ [TMP 
Me], 45.2 [TMP $\beta$ ], 53.1 [TMP $\alpha$ ], 69.1 [THF $\left.\alpha \mathrm{CH}_{2}\right], 69.5\left[\mathrm{C}_{5} \mathrm{H}_{5} \mathrm{Fe}\right], 71.7\left[\mathrm{C}_{5} \mathrm{H}_{4} \mathrm{Fe}\right]$, $77.1\left[\mathrm{C}_{5} \mathrm{H}_{4} \mathrm{Fe}\right]$.

${ }^{7} \mathrm{Li}$ NMR (155.46 MHz, $\left.\mathrm{C}_{6} \mathrm{D}_{12}, 300 \mathrm{~K}\right): \delta-0.56 \mathrm{ppm}$.

Calculated (\%) for $\mathrm{Al}_{1} \mathrm{C}_{31} \mathrm{Fe}_{1} \mathrm{H}_{53} \mathrm{Li}_{1} \mathrm{~N}_{1} \mathrm{O}_{1}$ : C, 68.25; $\mathrm{H}, 9.79 ; \mathrm{N}, 2.57$; found: $\mathrm{C}, 67.99$; H, 10.06; N, 3.11 .

Synthesis of $\left[\mathrm{THF} \cdot \mathrm{Li}(\mu-\mathrm{TMP}) \mathrm{Al}(i \mathrm{Bu})_{2}\right]_{2}\left(\mathrm{C}_{5} \mathrm{H}_{4}\right)_{2} \mathrm{Fe}(\mathbf{5})$

In a Schlenk flask, $n$ BuLi $(1.25 \mathrm{~mL}, 1.6 \mathrm{M}$ in hexanes, $2 \mathrm{mmol})$ was suspended in hexane $(10 \mathrm{~mL})$ and $\mathrm{TMP}(\mathrm{H})(0.34 \mathrm{~mL}, 2 \mathrm{mmol})$ was added via syringe, before $i \mathrm{Bu}_{2} \mathrm{AlCl}(0.38 \mathrm{~mL}, 2 \mathrm{mmol})$ was introduced via syringe producing a white suspension almost immediately. This was stirred for one hour and then filtered through Celite and glass wool to remove LiCl. In a separate Schlenk flask LiTMP was prepared in hexane $(10 \mathrm{~mL})$ from a mixture of $n \mathrm{BuLi}(1.25 \mathrm{~mL}, 2 \mathrm{mmol})$ and $\mathrm{TMP}(\mathrm{H})$ ( $0.34 \mathrm{~mL}, 2 \mathrm{mmol})$. The $i \mathrm{Bu}_{2} \mathrm{AlTMP}$ solution was added to the LiTMP solution via cannula to give a colourless solution. THF $(0.16 \mathrm{~mL}, 2 \mathrm{mmol})$ and ferrocene $(0.186 \mathrm{~g}$, $1 \mathrm{mmol}$ ) were added producing an orange solution which was stirred for 2 hours at reflux and then stored at $-30^{\circ} \mathrm{C}$ until a crop of orange crystals formed $(0.50 \mathrm{~g}$, not an absolute yield due to traces of $\mathbf{4}$ also being present).

${ }^{1} \mathrm{H}$ NMR (400.13 MHz, $\left.\mathrm{C}_{6} \mathrm{D}_{12}, 300 \mathrm{~K}\right): \delta 0.38\left[8 \mathrm{H}, \mathrm{m}, 4 \times \mathrm{CH}_{2}\right.$ of $\left.i \mathrm{Bu}\right], 0.75[4 \mathrm{H}, \mathrm{t}$, ${ }^{3} J(\mathrm{H}, \mathrm{H})=12.29 \mathrm{~Hz}, 2 \times \beta \mathrm{CH}_{2}$ of TMP], $1.10\left[24 \mathrm{H}, \mathrm{t},{ }^{3} J(\mathrm{H}, \mathrm{H})=7.55 \mathrm{~Hz}, 8 \times \mathrm{CH}_{3}\right.$ of $i \mathrm{Bu}], 1.25[12 \mathrm{H}, \mathrm{s}, 4 \mathrm{x}$ TMP Me], 1.29 [2H, m, $2 \mathrm{x} \gamma \mathrm{CH}$ of TMP], 1.32 [12H, s, $4 \mathrm{x}$ TMP Me], $1.47\left[4 \mathrm{H}, \mathrm{d},{ }^{3} J(\mathrm{H}, \mathrm{H})=12.38 \mathrm{~Hz}, 2 \times \mathrm{CH}_{2}\right.$ of TMP], $1.78[8 \mathrm{H}, \mathrm{s}, 4 \mathrm{x}$ $\beta \mathrm{CH}_{2}$ of THF], $1.84\left[2 \mathrm{H}, \mathrm{m}, 2 \mathrm{x} \gamma \mathrm{CH}\right.$ of TMP], $2.15\left[4 \mathrm{H}, \mathrm{sept},{ }^{3} J(\mathrm{H}, \mathrm{H})=6.37 \mathrm{~Hz}, 4 \mathrm{x}\right.$ 
$\mathrm{CH}$ of $i \mathrm{Bu}], 3.53\left[8 \mathrm{H}, \mathrm{s}, 4 \mathrm{x} \alpha \mathrm{CH}_{2}\right.$ of THF], $3.97\left[4 \mathrm{H}, \mathrm{s}, \mathrm{C}_{5} \mathrm{H}_{4} \mathrm{Fe}\right], 4.47[4 \mathrm{H}, \mathrm{s}$, $\left.\mathrm{C}_{5} \mathrm{H}_{4} \mathrm{Fe}\right]$.

${ }^{13} \mathrm{C}$ NMR (100.63 MHz, $\left.\mathrm{C}_{6} \mathrm{D}_{12}, 300 \mathrm{~K}\right): \delta 18.7$ [TMP $\gamma$ ], 25.9 [THF $\beta \mathrm{CH}_{2}$ ], 28.1 [CH${ }_{2} \underline{\mathrm{CHMe}}$ ] $, 29.4\left[\mathrm{CH}_{2} \mathrm{CHMe}_{2}\right], 29.7$ [TMP Me], $30.8\left[\underline{\mathrm{CH}}_{2} \mathrm{CHMe}_{2}\right], 36.8$ [TMP Me], 45.1 [TMP $\beta$ ], 53.0 [TMP $\alpha$ ], 69.2 [THF $\left.\alpha \mathrm{CH}_{2}\right], 74.7\left[\mathrm{C}_{5} \mathrm{H}_{4} \mathrm{Fe}\right], 77.4\left[\mathrm{C}_{5} \mathrm{H}_{4} \mathrm{Fe}\right]$.

${ }^{7} \mathrm{Li}$ NMR (155.46 MHz, $\left.\mathrm{C}_{6} \mathrm{D}_{12}, 300 \mathrm{~K}\right): \delta-0.69 \mathrm{ppm}$.

Calculated (\%) for $\mathrm{Al}_{2} \mathrm{C}_{52} \mathrm{Fe}_{1} \mathrm{H}_{96} \mathrm{Li}_{2} \mathrm{~N}_{2} \mathrm{O}_{2}: \mathrm{C}, 69.01 ; \mathrm{H}, 10.69 ; \mathrm{N}, 3.10$; found: $\mathrm{C}$, 68.54; H, 10.60; N, 3.39.

Synthesis of $\left[\mathrm{TMP}(\mathrm{H}) \cdot \mathrm{Li}(\mu-\mathrm{TMP}) \mathrm{Al}(i \mathrm{Bu})_{2}\right]_{2}\left(\mathrm{C}_{5} \mathrm{H}_{4}\right)_{2} \mathrm{Fe}(\mathbf{6})$

In a Schlenk flask, $n \mathrm{BuLi}(2.50 \mathrm{~mL}, 1.6 \mathrm{M}$ in hexanes, $4 \mathrm{mmol})$ was suspended in more hexane $(10 \mathrm{~mL})$ and $\mathrm{TMP}(\mathrm{H})(0.68 \mathrm{~mL}, 4 \mathrm{mmol})$ was added via syringe, before $i \mathrm{Bu}_{2} \mathrm{AlCl}(0.76 \mathrm{~mL}, 4 \mathrm{mmol})$ was introduced via syringe producing a white suspension almost immediately. This suspension was stirred for one hour and then filtered through Celite and glass wool to remove solid LiCl. In a separate Schlenk flask LiTMP was prepared in hexane $(10 \mathrm{~mL})$ from a mixture of $n \mathrm{BuLi}(2.50 \mathrm{~mL}, 4$ $\mathrm{mmol})$ and $\mathrm{TMP}(\mathrm{H})(0.68 \mathrm{~mL}, 4 \mathrm{mmol})$. Next, ferrocene $(0.186 \mathrm{~g}, 1 \mathrm{mmol})$ was added to the LiTMP solution followed immediately by the $i \mathrm{Bu}_{2} \mathrm{AlTMP}$ solution via cannula. This mixture was gently heated to give an orange solution and then stored at room temperature until a crop of orange crystals of 6 formed $(0.50 \mathrm{~g}, 48 \%)$.

${ }^{1} \mathrm{H}$ NMR (400.13 MHz, $\left.\mathrm{C}_{6} \mathrm{D}_{6}, 300 \mathrm{~K}\right): \delta 0.58$ [8H, m, 4 x $\mathrm{CH}_{2}$ of $i \mathrm{Bu}$ ], 0.66 [4H, br m, $2 \times \beta \mathrm{CH}_{2}$ of TMP], 1.04 [24H, s, $\left.8 \times \mathrm{TMP}(\mathrm{H}) \mathrm{Me}\right], 1.20\left[8 \mathrm{H}, \mathrm{t},{ }^{3} J(\mathrm{H}, \mathrm{H})=6.46 \mathrm{~Hz}, 4\right.$ $\mathrm{x} \beta \mathrm{CH}_{2}$ of TMP(H)], 1.34 [24H, m, 8 x $\mathrm{CH}_{3}$ of $\left.i \mathrm{Bu}\right], 1.43$ [24H, s, 8 x TMP Me], 1.49 [4H, m, $2 \times \gamma \mathrm{CH}$ of TMP], 1.50 [4H, br m, $2 \times \beta \mathrm{CH}_{2}$ of TMP], 1.77 [4H, br m, $2 \times$ 
$\gamma \mathrm{CH}$ of TMP(H)], $2.30[4 \mathrm{H}, \mathrm{m}, 4 \times \mathrm{CH}$ of $i \mathrm{Bu}], 4.15\left[4 \mathrm{H}, \mathrm{s}, \mathrm{C}_{5} \mathrm{H}_{4} \mathrm{Fe}\right], 4.29[4 \mathrm{H}$, br s, $\left.\mathrm{C}_{5} \mathrm{H}_{4} \mathrm{Fe}\right]$.

${ }^{13} \mathrm{C}$ NMR (100.63 MHz, $\left.\mathrm{C}_{6} \mathrm{D}_{6}, 300 \mathrm{~K}\right): \delta 18.2$ [TMP $\left.\gamma\right], 18.6$ [TMP(H) $\left.\gamma\right], 27.7$ $\left[\begin{array}{lllllll}\left.\mathrm{CH}_{2} \underline{\mathrm{C}} \mathrm{HMe}_{2}\right], & 28.3 & {\left[\mathrm{CH}_{2} \underline{\mathrm{CHMe}} \mathrm{HM}_{2}\right],} & 29.6 & {[\mathrm{TMP}} & \mathrm{Me}\end{array}\right], 30.0 \quad\left[\mathrm{CH}_{2} \mathrm{CHMe}_{2}\right], 30.6$ [ $\mathrm{CH}_{2} \mathrm{CHMe}_{2}$ ], 32.0 [TMP(H) Me], 37.1 [TMP Me], 38.6 [TMP(H) $\beta$ ], 45.5 [TMP $\beta$ ], $49.9[\mathrm{TMP}(\mathrm{H}) \alpha], 52.5[\mathrm{TMP} \alpha], 72.6\left[\mathrm{C}_{5} \mathrm{H}_{4} \mathrm{Fe}\right], 77.5\left[\mathrm{C}_{5} \mathrm{H}_{4} \mathrm{Fe}\right]$.

${ }^{7} \operatorname{Li}$ NMR (155.46 MHz, $\left.\mathrm{C}_{6} \mathrm{D}_{12}, 300 \mathrm{~K}\right): \delta 2.27 \mathrm{ppm}$.

\section{Associated Content}

\section{Supporting Information}

NMR spectra, X-ray collection data table and X-ray data in crystallographic file (CIF) format for compounds $1,2,4,5$ and 6 . This material is available free of charge via the Internet at http://pubs.acs.org

\section{Author Information}

\section{Corresponding Authors}

*E-mail: r.e.mulvey@strath.ac.uk

*E-mail: stuart.d.robertson@strath.ac.uk

\section{Acknowledgements}


The authors gratefully acknowledge the Royal Society (Wolfson Research Merit Award to R.E.M.), the Royal Society of Edinburgh (BP Trust Fellowship to S.D.R.), the European Research Council (ERC Starting Grant to E.H.), the University of Strathclyde/EPSRC (Doctoral Training Grants to D.L.R. and E.C.) and EPSRC (grant award nos. EP/K00183/1 and EP/L027313/1) for their kind sponsorship of this research. We also thank Dr. Ross W. Harrington and Mr. David V. Graham for their help with crystallographic data collection.

\section{Dedication}

In memory of Mike Lappert. The landscape of modern inorganic/organometallic chemistry is much richer due to his phenomenal seminal output.

\section{References}

1. (a) R. E. Mulvey, Acc. Chem. Res., 2009, 42, 743-755; (b) R. E. Mulvey, Dalton Trans., 2013, 42, 6676-6693.

2. (a) R. E. Mulvey, Organometallics, 2006, 25, 1060-1075; (b) R. E. Mulvey, F. Mongin, M. Uchiyama and Y. Kondo, Angew. Chem. Int. Ed., 2007, 46, 38023824.

3. G. Wittig, F. J. Meyer and G. Lange, Justus Liebigs Ann. Chem., 1951, 571, 167-201.

4. B. Haag, M. Mosrin, H. Ila, V. Malakhov and P. Knochel, Angew. Chem. Int. Ed., 2011, 50, 9794-9824.

5. (a) For a comprehensive library of bimetallic ate-type complexes see: A. Harrison-Marchand and F. Mongin, Chem. Rev., 2013, 113, 7470-7562; (b) For a review of their syntheses and reactivities see: F. Mongin and A. Harrison-Marchand, Chem. Rev., 2013, 113, 7563-7727.

6. (a) For their excellent contributions to alkali metal zincate chemistry see the following and references therein: Y. Kondo, J. V. Morey, J. C. Morgan, H. Naka, D. Nobuto, P. R. Raithby, M. Uchiyama and A. E. H. Wheatley, J. Am. Chem. Soc., 2007, 129, 12734-12738; (b) For their excellent contributions to alkali metal aluminate chemistry see the following and references therein: $H$. Naka, J. V. Morey, J. Haywood, D. J. Eisler, M. McPartlin, F. Garcia, H. Kudo, Y. Kondo, M. Uchiyama and A. E. H. Wheatley, J. Am. Chem. Soc., 
2008, 130, 16193-16200; (c) For a review of lithium zincates see: A. E. H. Wheatley, New. J. Chem., 2004, 28, 435-443; (d) For a review of metalation using lithium cuprates see: P. J. Harford, A. J. Peel, F. Chevallier, R. Takita, F. Mongin, M. Uchiyama and A. E. H. Wheatley, Dalton Trans., 2014, 43, 14181-14203; (e) M. Uchiyama and C. Wang, Top. Organomet. Chem., 2014, 47, 159-202; (f) Y. Kondo, M. Shilai, T. Sakamoto and M. Uchiyama, J. Am. Chem. Soc., 1999, 121, 3539-3540.

7. (a) R. E. Mulvey and S. D. Robertson, Top. Organomet. Chem., 2013, 45, 103-140; (b) R. E. Mulvey and S. D. Robertson, Top. Organomet. Chem., 2014, 47, 129-158.

8. A. J. Martinez-Martinez, A. R. Kennedy, R. E. Mulvey and C. T. O'Hara, Science, 2014, 346, 834-838.

9. A. J. Martinez-Martinez, D. R. Armstrong, B. Conway, B. J. Fleming, J. Klett, A. R. Kennedy, R. E. Mulvey, S. D. Robertson and C. T. O'Hara, Chem. Sci., 2014, 5, 771-781.

10. V. L. Blair, L. M. Carella, W. Clegg, B. Conway, R. W. Harrington, L. M. Hogg, J. Klett, R. E. Mulvey, E. Rentschler and L. Russo, Angew. Chem. Int. Ed., 2008, 47, 6208-6211.

11. R. E. Mulvey, Chem. Commun., 2001, 1049-1056.

12. W. Clegg, K. W. Henderson, A. R. Kennedy, R. E. Mulvey, C. T. O'Hara, R. B. Rowlings and D. M. Tooke, Angew. Chem. Int. Ed., 2001, 40, 3902-3905.

13. P. C. Andrikopolous, D. R. Armstrong, W. Clegg, C. J. Gilfillan, E. Hevia, A. R. Kennedy, R. E. Mulvey, C. T. O'Hara, J. A. Parkinson and D. M. Tooke, J. Am. Chem. Soc., 2004, 126, 11612-11620.

14. K. W. Henderson, A. R. Kennedy, R. E. Mulvey, C. T. O'Hara and R. B. Rowlings, Chem. Commun., 2001, 1678-1670.

15. M. F. Lappert and D.-S. Liu, J. Organomet. Chem., 1995, 500, 203-217.

16. M. Lappert, P. Power, A. Protchenko and A. Seeber, Metal Amide Chemistry, John Wiley \& Sons Ltd, Hoboken, 2008.

17. C. F. Caro, M. F. Lappert and P. G. Merle, Coord. Chem. Rev., 2001, 219-221, 605-663.

18. (a) P. M. Druce, B. M. Kingston, M. F. Lappert, T. R. Spalding and R. C. Srivastava, J. Chem. Soc. (A), 1969, 2106-2110; (b) P. B. Hitchcock, M. F. Lappert and C. R. C. Milne, J. Chem. Soc. Dalton Trans., 1981, 180-186; (c) M. F. Lappert, C. J. Pickett, P. I. Riley and P. I. W. Yarrow, J. Chem. Soc. Dalton Trans., 1981, 805-813.

19. H. R. Barley, W. Clegg, S. H. Dale, E. Hevia, G. W. Honeyman, A. R. Kennedy and R. E. Mulvey, Angew. Chem. Int. Ed., 2005, 44, 6018-6021.

20. A. S. Perucha, J. Heilmann-Brohl, M. Bolte, H.-W. Lerner and M. Wagner, Organometallics, 2008, 28, 6170-6177.

21. N. Seidel, K. Jacob, P. Zanello and M. Fontani, J. Organomet. Chem., 2001, 620, 243-248.

22. E. Hevia, A. R. Kennedy and M. D. McCall, Dalton Trans., 2012, 41, 98-103.

23. W. Clegg, B. Conway, P. Garcia-Alvarez, A. R. Kennedy, J. Klett, R. E. Mulvey and L. Russo, Dalton Trans., 2010, 39, 62-65.

24. B. Wrackmeyer, E. V. Klimkina, T. Ackermann and W. Milius, Inorg. Chem. Commun., 2007, 10, 743-747.

25. R. D. Rogers, W. J. Cook and J. L. Atwood, Inorg. Chem., 1979, 18, 279-282.

26. H. Braunschweig, G. K. B. Clentsmith, S. Hess, T. Kupfer and K. Radacki, Inorg. Chim. Acta, 2007, 360, 1274-1277. 
27. B. Wrackmeyer, E. V. Klimkina and W. Milius, Eur. J. Inorg. Chem., 2009, 3163-3171.

28. K. Knabel, I. Krossing, H. Nöth, H. Schwenk-Kircher, M. SchmidtAmelunxen and T. Seifert, Eur. J. Inorg. Chem., 1998, 1095-1114.

29. J. A. Schachner, C. L. Lund, J. W. Quail and J. Müller, Acta Crystallogr., 2005, E61, m682-m684.

30. B. Wrackmeyer, E. V. Klimkina and W. Milius, Eur. J. Inorg. Chem., 2009, 3155-3162.

31. C. L. Lund, J. A. Schachner, J. W. Quail and J. Müller, Organometallics, 2006, 25, 5817-5823.

32. J. A. Schachner, C. L. Lund, J. W. Quail and J. Müller, Organometallics, 2005, 24, 785-787.

33. H. Braunschweig, C. Burschka, G. K. B. Clentsmith, T. Kupfer and K. Radacki, Inorg. Chem., 2005, 44, 4906-4908.

34. R. Sun, L. Wang, H. Yu, Z. ul-Abdin, Y. Chen, J. Huang and R. Tong, Organometallics, 2014, 33, 4560-4573.

35. M. F. R. Fouda, M. M. Abd-Elzaher, R. A. Abdelsamaia and A. A. Labib, Appl. Organomet. Chem., 2007, 21, 613-625.

36. D. R. van Staveren and N. Metzler-Nolte, Chem. Rev., 2004, 104, 5931-5986.

37. L.-X. Dai, T. Tu, S.-L. You, W.-P. Deng and X.-L. Hou, Acc. Chem. Res., 2003, 36, 659-667.

38. Organometallics recently dedicated an entire issue to ferrocene entitled Ferrocene - Beauty and Function. See the following for more details: K. Heinze and H. Lang, Organometallics, 2013, 32, 5623-5625.

39. P. C. Andrikopoulos, D. R. Armstrong, H. R. L. Barley, W. Clegg, S. H. Dale, E. Hevia, G. W. Honeyman, A. R. Kennedy and R. E. Mulvey, J. Am. Chem. Soc., 2005, 127, 6184-6185.

40. L. Yang, D. R. Powell and R. P. Houser, Dalton Trans., 2007, 955-964.

41. J. J. Morris, B. C. Noll, G. W. Honeyman, C. T. O'Hara, A. R. Kennedy, R. E. Mulvey and K. W. Henderson, Chem. Eur. J., 2007, 13, 4418-4432.

42. R. E. Dinnebier, U. Behrens and F. Olbrich, Organometallics, 1997, 16, 38553858.

43. M. L. Cole, C. Jones and P. C. Junk, J. Chem. Soc. Dalton Trans., 2002, 896905.

44. C. M. Widdifield, J. A. Tang, C. L. B. Macdonald and R. W. Schurko, Magn. Reson. Chem., 2007, 45, S116-S128.

45. J. Hey, D. M. Andrada, R. Michel, R. A. Mata and D. Stalke, Angew. Chem. Int. Ed., 2013, 52, 10365-10369.

46. T. Aoyagi, H. M. M. Shearer, K. Wade and G. Whitehead, J. Chem. Soc. Chem. Commun., 1976, 164-165.

47. A similar $\mathrm{Na}-\mathrm{Cp}$ interaction in a bimetallic $\mathrm{Na} / \mathrm{Sn}$ complex results in considerable concomitant elongation of the Sn-Cp distance: M. G. Davidson, D. Stalke and D. S. Wright, Angew. Chem. Int. Ed., 1992, 31, 1226-1227.

48. A. Reichert, J. Schmidt, M. Bolte, M. Wagner and H.-W. Lerner, Z. Anorg. Allg. Chem., 2013, 639, 1083-1086.

49. (a) B. Conway, E. Hevia, J. Garcia-Alvarez, D. V. Graham, A. R. Kennedy and R. E. Mulvey, Chem. Commun., 2007, 5241-5243; (b) B. Conway, J. Garcia-Alvarez, E. Hevia, A. R. Kennedy, R. E. Mulvey and S. D. Robertson, Organometallics, 2009, 17, 6725-6730; (c) E. Crosbie, P. Garcia-Alvarez, A. R. Kennedy, J. Klett, R. E. Mulvey and S. D. Robertson, Angew. Chem. Int. 
Ed., 2010, 49, 9388-9391; (d) R. E. Mulvey, D. R. Armstrong, B. Conway, E. Crosbie, A. R. Kennedy and S. D. Robertson, Inorg. Chem., 2011, 50, 1224112251; (e) B. Conway, E. Crosbie, A. R. Kennedy, R. E. Mulvey and S. D. Robertson, Chem. Commun., 2012, 48, 4674-4676; (f) E. Crosbie, A. R. Kennedy, R. E. Mulvey and S. D. Robertson, Dalton Trans., 2012, 41, 18321839; (g) R. Campbell, E. Crosbie, A. R. Kennedy, R. E. Mulvey, R. A. Naismith and S. D. Robertson, Aust. J. Chem., 2013, 66, 1189-1201.

50. D. R. Armstrong, E. Crosbie, E. Hevia, R. E. Mulvey, D. L. Ramsay and S. D. Robertson, Chem. Sci., 2014, 5, 3031-3045.

51. G. Dayaker, A. Sreeshailam, F. Chevallier, T. Roisnel, P. Radha Krishna and F. Mongin, Chem. Commun., 2010, 46, 2862-2864.

52. For mechanistic insight into why bulky TMP complexes cannot cocomplex to give a homoleptic ate base see: D. R. Armstrong, A. R. Kennedy, R. E. Mulvey, J. A. Parkinson and S. D. Robertson, Chem. Sci., 2012, 3, 2700-2707.

53. U. Braun, T. Habereder and H. Nöth, Eur. J. Inorg. Chem., 2004, 3629-3643.

54. J. Garcia-Alvarez, E. Hevia, A. R. Kennedy, J. Klett and R. E. Mulvey, Chem. Commun., 2007, 2402-2404.

55. D. R. Armstrong, A. R. Kennedy, R. E. Mulvey and R. B. Rowlings, Angew. Chem. Int. Ed., 1999, 38, 131-133.

56. (a) E. Hevia, D. J. Gallagher, A. R. Kennedy, R. E. Mulvey, C. T. O'Hara and C. Talmard, Chem. Commun., 2004, 2422-2423; (b) P. C. Andrikopoulos, D. R. Armstrong, D. V. Graham, E. Hevia, A. R. Kennedy, R. E. Mulvey, C. T. O'Hara and C. Talmard, Angew. Chem. Int. Ed., 2005, 44, 3459-3462.

57. D. R. Armstrong, W. Clegg, S. H. Dale, D. V. Graham, E. Hevia, L. M. Hogg, G. W. Honeyman, A. R. Kennedy and R. E. Mulvey, Chem. Commun., 2007, 598-600.

58. A. A. Fyfe, A. R. Kennedy, J. Klett and R. E. Mulvey, Angew. Chem. Int. Ed., 2011, 50, 7776-7780.

59. (a) M. Uchiyama, Y. Matsumoto, D. Nobuto, T. Furuyama, K. Yamaguchi and K. Morokuma, J. Am. Chem. Soc., 2006, 128, 8748-8750; (b) W. Clegg, B. Conway, E. Hevia, M. D. McCall, L. Russo and R. E. Mulvey, J. Am. Chem. Soc., 2009, 131, 2375-2384; (c) D. R. Armstrong, J. Garcia-Alvarez, D. V. Graham, G. W. Honeyman, E. Hevia, A. R. Kennedy and R. E. Mulvey, Chem. Eur. J., 2009, 15, 3800-3807; (d) D. R. Armstrong, V. L. Blair, W. Clegg, S. H. Dale, J. Garcia-Alvarez, G. W. Honeyman, E. Hevia, R. E. Mulvey and L. Russo, J. Am. Chem. Soc., 2010, 132, 9480-9487.

60. R. E. Mulvey and J. A. Garden, Di-tert-butylzinc, e-EROS Encyclopedia of Reagents for Organic Synthesis, 2014, 1-4.

61. G. M. Sheldrick, Acta Crystallogr., 2007, A64, 112-122. 